\title{
Income tax progressivity, growth, income inequality and welfare
}

\author{
Cruz A. Echevarría
}

Received: 10 May 2013 / Accepted: 13 November 2014 / Published online: 23 December 2014 (C) The Author(s) 2014. This article is published with open access at SpringerLink.com

\begin{abstract}
This paper analyzes the effects of personal income tax progressivity on long-run economic growth, income inequality and social welfare. The quantitative implications of income tax progressivity increments are illustrated for the US economy under three main headings: individual effects (reduced labor supply and savings, and increased dispersion of tax rates); aggregate effects (lower GDP growth and lower income inequality); and welfare effects (lower dispersion of consumption across individuals and higher leisure levels, but also lower growth of future consumption). The social discount factor proves to be crucial for this third effect: a higher valuation of future generations' well-being requires a lower level of progressivity. Additionally, if tax revenues are used to provide a public good rather than just being discarded, a higher private valuation of such public goods will also call for a lower level of progressivity.
\end{abstract}

Keywords Growth $\cdot$ Income tax progressivity $\cdot$ Income inequality $\cdot$ Welfare

JEL Classification $\mathrm{H} 20 \cdot \mathrm{O} 41$

\section{Introduction}

Income tax progressivity helps to attain a more equal distribution of income, wealth and consumption. Additionally, in the presence of uninsurable uncertainty (whether because it is of aggregate nature, or being of idiosyncratic type, insurance markets are missing), progressive taxation provides some partial insurance and less volatile household consumption over time. The counterpart, however, is that progressive taxa-

C. A. Echevarría $(\varangle)$

University of the Basque Country UPV/EHU, Avda. Lehendakari Aguirre 83, Bilbao 48015, Spain e-mail: cruz.echevarria@ehu.es 
tion introduces incentive distortions for labor supply, saving and investment decisions of private economic agents.

The optimal degree of progressivity of income taxation has been, and still is, a live issue among academic researchers which point out challenging results in several directions. But it is also an issue of concern among policy practitioners as the recent crisis has forced many governments to look for new sources of revenue, and higher and more progressive taxes seem to be on their schedules, raising the corresponding policy debate.

The issue dates back to Mirrlees (1971) seminal paper, so that the economic literature has produced some major works on the subject since then. Hubbard and Judd (1986) find that an exemption and a higher marginal tax rate can in some cases improve efficiency relative to a proportional tax, so that some degree of progressivity may be desirable. Conesa and Krueger (2006) find that the optimal US total income tax code is well approximated by a flat tax rate of $17.2 \%$ and a fixed deduction of about $\$ 9,400$. In a similar set-up, Conesa et al. (2009) conclude that, also for the US case, the optimal capital income tax (flat) rate is $36 \%$, while the optimal progressive labor income tax consists of a flat tax of $23 \%$ with a deduction of $\$ 7,200$. In a closely related paper, Peterman (2014) finds that the introduction of human capital causes a $4.7 \%$ increase in the optimal capital tax and a notably flatter optimal labor income tax. Carroll and Young (2011) find that increases in the progressivity of the income tax schedule are associated with long-run distributions with greater aggregate income, wealth, capital and labor, and lower income inequality and higher wealth inequality. Diamond and Saez (2011) and Kindermann and Krueger (2014) suggest that the optimal labor income tax rate for the top earners would imply a marginal tax rate as high as $73 \%$ or even $90 \%$. Bakis et al. (2014) find that when the transitional dynamics are ignored, the optimal tax policy for the long-run steady state is moderately regressive; when the transition path is considered, however, the optimal tax reform is much more progressive. Along similar lines, some other authors suggest that the revenue-maximizing marginal tax rate for the top earners should be at least $36.9 \%$ (see Guner et al. 2014b), or even around $53 \%$ (see Badel and Huggett 2014). It is worth pointing out that a feature common to all these previous references is that economic growth is either absent or made exogenous.

Switching to works of endogenous growth, and focusing on the US economy, Caucutt et al. (2003) build up an OLG model where growth is driven by human capital investment. They find that reductions in the progressivity of labor income tax can in themselves have positive growth effects and decrease inequality: the annual per capita growth rate along the balanced-growth path would rise by up to $0.52 \%$ by eliminating progressivity. Benabou (2002) sets up an infinitely-lived agents model of human capital accumulation, concluding that long run growth would be maximized if the average marginal tax rate for labor income were $34.8 \%$, giving rise to a $0.5 \%$ increment in the long run growth rate (see Tang and King 2005 for a correction). Li and Sarte (2004) modify Rebelo (1991) and Barro (1990) original endogenous growth models to account for progressive taxes, finding that the progressivity decrease implied by the 1986 Tax Reform Act helped raise U.S. per capita GDP growth between 0.12 and $0.34 \%$. 
Echevarria (2012) builds a two-period $O L G$ economy with aggregate uncertainty and in which young individuals' savings in the form of physical capital drive growth through an $A K$ technology, individuals' age being the only (trivial) source of heterogeneity as individuals pertaining to the same generation are all alike. Assuming inelastic labor supply and recursive preferences, necessary and sufficient conditions are obtained for the introduction of a progressive income tax in a flat income tax economy to induce a reduction in the growth rate, the intertemporal rate of substitution in consumption proving to be a key parameter. The model is numerically illustrated for the U.S. economy, showing that the long-run GDP growth rate would be maximized under a regressive income tax.

In this paper I set up an economy model that partly draws on Echevarria (2012). As in that paper, I assume a two-period, OLG economy populated by non-altruistic individuals in which government expenditure, representing a constant fraction of GDP, is financed via a progressive personal income tax, physical capital accumulation in an $A K$ fashion being the engine of growth. Therefore, this set up differs from that in Caucutt et al. (2003) where human capital accumulation gives the growth generating mechanism. Once physical capital accumulation is adopted, the $A K$ specification proves useful as it simplifies both the algebra and the numerical computation because transitional dynamics are precluded.

Additionally, here I introduce some added features. First, young individuals' labor supply is elastic. This is a must ingredient when, as in this paper, labor and capital income end up being taxed differently. This is so not because labor and capital income are taxed separately as in Conesa et al. (2009), but because in the simple economy that I build up young (active) individuals live only on labor income, old (retired) individuals live only on capital income, and, in general, young and old individuals' incomes are different. ${ }^{1}$ This assumption alone implies one key difference with respect to Echevarria (2012). The (negative) growth effect of income tax progressivity is reinforced, as a higher tax progressivity is shown to lead to substantial reductions in individuals' labor supply which further reduce young individuals' savings.

Second, I assume that individuals differ in their skills or innate labor productivities, thereby allowing for an intra-generational heterogeneity absent in that paper and which, in turn, allows us to approximate the observed income distribution. Along the same lines, market or before-tax income distribution now becomes endogenous, as the tax policy now does influence labor and savings decisions of different type individuals in a different way.

Third, perfect foresight is assumed. When risk aversion is properly treated, so that attitudes toward risk and intertemporal consumption substitutability are independently modelled, previous works in the literature have proven that the effect of income taxation on the equilibrium growth rate mainly depends on the elasticity of intertemporal substitution in consumption, while the role played by aggregate uncertainty or individuals' risk aversion is a minor one. In other words, deterministic models offer a reasonable first approximation to the effects of taxes on growth. See, e.g. Echevarria (2012, 2013), Mauro (1995) or Smith (1996).

\footnotetext{
1 Gervais (2009) proves that progressive taxation can imitate optimal age-dependent proportional tax rates to some extent as earnings vary over the lifetime of individuals.
} 
Fourth, the progressive tax schedule introduced by Li and Sarte (2004) is here replaced by that in Heathcote et al. (2014). Despite being similar in nature, the latter formulation allows one to set both a lower and an upper bound on the progressivity index which have natural interpretations: proportional taxation and maximum redistribution in that net-of-tax incomes are equalized across taxpayers, respectively.

And, fifth, when discussing welfare implications of tax progressivity, a special reference is made to the destination that the government selects for tax proceeds. Contrary to the usual assumption that tax revenues are just wasted (so that no public investment is made nor a consumption good entering the individuals' utility function is provided), in this paper I consider the case in which tax revenues are used to publicly provide a consumption good. ${ }^{2}$ As I will show, even when this implies no change for the equilibrium private allocation nor the equilibrium growth rate, the social welfare maximizing progressivity of the income tax code does change.

The model here introduced is, therefore, characterized by basic features that, although borrowed from previous works, when jointly considered make it depart from those. It is an overlapping generations economy, but as opposed to Caucutt et al. (2003), households are non-altruistic and have perfect foresight, growth is generated by physical capital accumulation, the progressivity of the income tax applies not only to labor income, but also to capital income, and progressive tax rates are endogenously obtained rather than ex ante imposed. And unlike Echevarria (2012), perfect foresight, intra-generational heterogeneity and elastic labor supply are assumed.

The results that I obtain are of a quantitative nature. The model economy is first calibrated to mimic some stylized facts of the U.S. economy. Then, the following revenue-neutral tax experiment is run: assuming that aggregate tax revenues are a constant fraction of the economy's aggregate output, I analyze both the individuals' and the aggregate economy's responses to (unannounced) changes in the progressivity of the income tax code. The numerical results obtained are an illustration of the effects of income tax progressivity upon economic growth, income inequality, and social welfare.

The main predictions that the numerical analysis suggests fall under three main categories: individual, aggregate, and social welfare related. A summary follows.

Concerning individual effects, increases in income tax progressivity induce drops in labor supply of all types of individuals, and reductions in savings of all individuals except for the least skilled, as a result of higher average tax rates borne by all individuals except for the least skilled and lower average tax rates borne by the least skilled who become subsidized.

Regarding aggregate effects, increments in income tax progressivity lead to a fall in aggregate savings, which (given the growth mechanism in this model economy) implies a lower equilibrium growth rate. Thus, eliminating the progressivity and moving to a flat tax regime would raise the equilibrium annual growth rate of per capita GDP from 1.92 to $1.95 \%$. Additionally, higher income tax progressivity reduces the inequality in the distribution of both pre-tax and after-tax incomes. Thus, introducing a proportional

$2 \mathrm{Li}$ and Sarte (2004) is the exception, of course, as one of the models they study draws on Barro (1990). 
income tax code in the benchmark economy would increase the Gini indices of market and net-of-tax incomes by 1 and $3.8 \%$, respectively.

Finally, concerning social welfare effects, optimality imposes a political choice as income tax progressivity leads to three effects: two positive, one negative. First, a more equal distribution of net income and consumption levels across different types of individuals. Second, higher levels of leisure. And, third, a lower growth rate of consumption. The size of this negative effect crucially depends on the social discount factor: as the social planner values more future generations' well-being, the optimal level of the income tax progressivity will fall. Thus, if the social discount factor is almost zero, then the optimal progressivity level will almost imply complete income redistribution with a welfare gain equivalent to a $62.45 \%$ increment in lifetime consumption and a negligible (close to zero) annual growth rate of per capita GDP. However, if the social discount factor is high enough (around 1.2), the progressivity level will sharply fall (although still above the benchmark economy value). In this case, the resulting small fall in the annual growth rate of per capita GDP (from 1.92 to $1.87 \%$ ) would imply a welfare loss equivalent to a $15.01 \%$ fall in lifetime consumption.

In addition, if the government tax proceeds are devoted to the public provision of some private good rather than discarded, the optimal progressivity level will also depend on how households value this public provision relative to private consumption. Thus, a higher valuation implies a lower optimal progressivity level, as progressivity also reduces the growth rate of the government provided consumption. At any rate, and for the parameter values considered, optimality requires some degree of progressivity. And, not only do the optimal progressivity levels themselves depend negatively such social and individual preference parameters, but so also do the respective quantitative gains.

The rest of the paper is organized as follows. Section 2 describes the economy. Section 3 solves the equilibrium growth rate. Section 4 discusses welfare analysis. Section 5 provides numerical results. Section 6 concludes. An "Appendix" discusses the results under the assumption that the government publicly provides a private consumption good financed with the tax proceeds.

\section{The economy}

There are two sectors in the economy: a private one (households and firms) which makes its decisions in a perfectly competitive market framework; and a government which levies a progressive income tax to finance some exogenous level of expenditure which, in this benchmark economy, is neither productive nor enters households' preferences. Later on, as a sensitivity analysis exercise, I will discuss how this assumption might affect the results of the paper, in particular those related to individuals' welfare.

As for households, this is an OLG economy, populated by a continuum of young individuals and a continuum of old individuals which coexist at any time, in which population is assumed to grow at an exogenous, constant rate, $m \geq 0$. Therefore, individuals differ in age and in their innate labor ability. This way, income redistribution through progressive taxation takes place across individuals of different generations and of different labor productivities living at the same time. 
The productive sector is represented by a continuum of competitive firms of measure one. All firms use the same production technology of constant returns to scale in capital and labor and are exposed to a positive externality given by the aggregate stock of capital per unit of labor. The appropriate choice of parameters will make firms exhibit an aggregate $A K$ technology in equilibrium, thereby allowing for the existence of sustained growth.

\subsection{Households}

Suppose an $i$-th type individual born at time $t$ who lives for 2 periods and obtains utility from young and old period consumption $\left(c_{1, t}^{i}\right.$ and $c_{2, t+1}^{i}$, respectively) and disutility from young period labor, $n_{t}^{i} \in(0,1)$, where total time endowment per period is normalized to unity. In their second period, individuals are assumed to be retired. ${ }^{3}$ More precisely, I assume that $i$-th individual's preferences are represented by the following utility function.

$$
U\left(c_{1, t}^{i}, c_{2, t+1}^{i}, n_{t}^{i}\right)=\frac{\left(c_{1, t}^{i}\right)^{1-\sigma_{1}}\left(1-n_{t}^{i}\right)^{\sigma_{2}}}{1-\sigma_{1}}+\beta \frac{\left(c_{2, t+1}^{i}\right)^{1-\sigma_{1}}}{1-\sigma_{1}},
$$

for $i=1,2, \ldots, I, I$ denoting the number of individual types, where $\beta \in(0,1)$ denotes the subjective discount factor, and parameters $\sigma_{1}$ and $\sigma_{2}$ are such that if $\sigma_{1} \in(0,1)$, then $\sigma_{2} \in(0,1)$; and if $\sigma_{1}>1$, then $\sigma_{2}<0$. Some remarks follow Eq. (1). First, the intertemporal elasticity of substitution for consumption is given by IES $=1 / \sigma_{1}$. And, second, the preferences over life-time consumption and leisure there represented are compatible with balanced growth along the steady state. Note that labor supply along the balanced growth path must be constant, while per capita first-period consumption and the wage rate grow at the same rate: i.e. the marginal rate of substitution between $c_{t}^{i}$ and $1-n_{t}^{i}$ must fall at the same rate as the inverse of the (net-of-tax) wage rate.

Progressive income taxation implies that individuals with different incomes face different tax rates. In this simple economy, there are two sources of individual heterogeneity: age and labor skills. Thus, the average tax rate that a young (resp. old) $i$-th type individual is charged is denoted by $\tau_{1}^{i}$ (resp. $\tau_{2}^{i}$ ), its precise nature being discussed below. Tax rates are assumed time-invariant for simplicity, so that they are not affected by a time subscript. ${ }^{4}$

Denoting the $i$-th type individual's skill parameter by $\theta^{i}>0$, the first-period savings at $t$ by $s_{t}^{i}$, the wage rate per unit of labor at $t$ by $w_{t}$, and the net-of-depreciation interest rate paid at $t+1$ by $r_{t+1}$, one obtains the first- and second-period individual budget constraints as

3 The first subscript denotes age (1, young; 2, adult) and the second subscript denotes calendar time. Superscript $i$ trivially denotes individual's type. Given that second period labor supply is identically equal to $1, n_{t}^{i}$ does not require a second subscript.

4 In this paper I am assuming that all sources of income are aggregated to assess an individual's tax bill. It corresponds to what is known in the literature as a "comprehensive" or "global income tax", as opposed to a "schedular or dual income tax" (see Kleinbard 2010, p. 41). 


$$
c_{1, t}^{i}+s_{t}^{i}=\left(1-\tau_{1}^{i}\right) \theta^{i} n_{t}^{i} w_{t},
$$

and

$$
c_{2, t+1}^{i}=\left[1+\left(1-\tau_{2}^{i}\right) r_{t+1}\right] s_{t}^{i},
$$

respectively for $i=1,2, \ldots, I$.

Thus, substituting $c_{1, t}^{i}$ and $c_{2, t+1}^{i}$ from Eqs. (2) and (3), respectively, into the objective function in Eq. (1), and maximizing the resulting equation with respect to $s_{t}^{i}$ and $n_{t}^{i}$ yields the following set of two first-order necessary (and, along with Eqs. (2)-(3), sufficient) optimality conditions

$$
\left(c_{1, t}^{i}\right)^{-\sigma_{1}}\left(1-n_{t}^{i}\right)^{\sigma_{2}}=\beta\left(c_{2, t+1}^{i}\right)^{-\sigma_{1}}\left[1+\left(1-\tau_{2}^{i}-s_{t}^{i} \times \frac{\partial \tau_{2}^{i}}{\partial s_{t}^{i}}\right) r_{t+1}\right],
$$

and

$$
\left(1-n_{t}^{i}\right) \theta^{i} w_{t}\left[1-\tau_{1}^{i}-n_{t}^{i} \times \frac{\partial \tau_{1}^{i}}{\partial n_{t}^{i}}\right]=\frac{\sigma_{2}}{1-\sigma_{1}} c_{1, t}^{i},
$$

for $i=1,2, \ldots, I$. Equation (4) represents the standard Euler equation for optimal consumption plans for two consecutive periods. Notice the term $\partial \tau_{2}^{i} / \partial s_{t}^{i}$ on the righthand side of Eq. (4): if the income tax schedule is progressive, the tax rate that an $i$-th type old individual faces becomes endogenous (increasing in his/her savings, $s_{t}^{i}$ ). Equation (5) represents the standard optimal consumption-leisure choice: the marginal utility of consumption times the foregone consumption units as a result of one additional unit of leisure, the latter being $\theta^{i} w_{t}\left(1-\tau_{1}^{i}-n_{t}^{i} \times \frac{\partial \tau_{1}^{i}}{\partial n_{t}^{i}}\right)$, must equal the marginal utility of leisure. Similarly to Eq. (4), the term $\partial \tau_{1}^{i} / \partial n_{t}^{i}$ must show up in Eq. (5), denoting the endogenous nature of the tax rate charged to an $i$-th type young individual.

\subsection{Firms}

Let us suppose that a profit maximizing firm $f$ acts competitively in the output and production factor (capital and labor) markets without adjustment costs in production inputs. Formally, the problem this firm faces at time $t$ is written as

$$
\begin{gathered}
\max _{\left\{Y_{t}^{f}, N_{t}^{f}, K_{t}^{f}\right\}} Y_{t}^{f}-w_{t} N_{t}^{f}-\left(r_{t}+\delta\right) K_{t}^{f} \\
\text { s.t. } \quad Y_{t}^{f}=A\left(K_{t}^{f}\right)^{\alpha}\left(N_{t}^{f}\right)^{1-\alpha} k_{t}^{1-\alpha}, \quad A>0
\end{gathered}
$$

where $Y_{t}^{f}$ denotes output, $N_{t}^{f}$ denotes labor (in efficiency units), $K_{t}^{f}$ denotes physical capital, $\alpha \in(0,1)$ denotes the capital income share, and $\delta$ stands for the physical capital depreciation rate. Some remarks concerning production technology follow. First, I assume that all firms (uniformly distributed on the interval $[0,1]$ ) exhibit the 
same production technology. Second, I also assume that there is a positive externality in the production process so that $f$-th firm's output depends not only on the inputs hired by that firm, but also on the average number of units of capital per unit of labor (in efficiency units), for the whole economy, $k_{t} \equiv K_{t} / N_{t}$, where $K_{t} \equiv \int_{0,1]} K_{t}^{f} d f$, and $N_{t} \equiv \int_{0,1]} N_{t}^{f} d f$. The intended consequence is that this economy will display an $A K$ technology in equilibrium, where $Y_{t}=A K_{t}$, thereby allowing for sustained economic growth which will be constant, i.e. with no transitional dynamics. ${ }^{5}$

The solution to the problem in Eq. (6) is given by the factor price equations

$$
r_{t}=\alpha A-\delta, \quad \text { and } \quad w_{t}=(1-\alpha) A k_{t} .
$$

Thus, the user cost of capital will be constant, $\alpha A$, but the wage rate, $w_{t}=(1-\alpha) A k_{t}$, will grow at the same rate as the aggregate stock of capital per unit of labor.

\subsection{Government}

A government sector is introduced in the following way: it taxes capital and labor incomes with the same tax code, capital depreciation is completely deductible, and tax revenues are used to finance an exogenous stream of public expenditure, $G_{t}$, which (for the sake of analytical convenience) is expressed as a constant proportion, $\gamma>0$, of aggregate output (i.e. $G_{t}=\gamma Y_{t}$ ).

Concerning the income tax code, I will suppose this to be of the particular class introduced by Benabou (2002) and Heathcote et al. (2014), where the tax rate that the $i$-th individual is charged depends on how his/her income, $y_{a, t}^{i}$, is related to average (i.e. per capita) income, $y_{t}{ }^{6}$ Thus, the average tax rate paid by individual $i$ with age $a$ and income $y_{a, t}^{i}$ is given by

$$
\tau_{a}^{i}=1-\xi\left(\frac{y_{a, t}^{i}}{y_{t}}\right)^{-\phi},
$$

for $i=1,2, \ldots I$, for some $\xi>0$ (to be endogenously obtained when solving the macroeconomic equilibrium), and $\phi \geq 0$, where $a=\{1,2\}$ for young and old individuals respectively. Thus, Eq. (8) implies that the marginal tax rate faced by this individual, $\partial\left(\tau_{a}^{i} \times y_{a, t}^{i}\right) / \partial y_{a, t}^{i}$, equals $\hat{\tau}_{a}^{i}=1-(1-\phi)\left(1-\tau_{a}^{i}\right)$. This way, the ratio $\left(\hat{\tau}_{a}^{i}-\tau_{a}^{i}\right) /\left(1-\tau_{a}^{i}\right)=\phi$ provides us with a natural indicator of the progressivity of the tax schedule, independent of the income level at which it is evaluated. Note that if $\phi=0$, income taxation is proportional and $\hat{\tau}_{a}^{i}=\tau_{a}^{i} ; \phi>0$ if and only $d \tau_{a}^{i} / d y_{a, t}^{i}>0$,

\footnotetext{
5 Despite the fact that some studies have questioned the empirical relevance of the $A K$ growth model, e.g. Jones (1995), there are numerous empirical works in the economic literature that have found this approach an appropriate way to explain observed growth data. See, among others, McGrattan (1998), Li (2002) or Cunado et al. (2009), for the standard one-sector version of the $A K$ model, or Farmer and Lahiri (2006) who consider a two-sector extended version of the model.

6 For alternative ways to model income tax progressivity, including the one I follow here see Guner et al. (2014a). They consider four specifications of the average tax rates and estimate them for the U.S. economy.
} 
i.e. the tax schedule is progressive; and if $\varphi=1$, after-tax income for $i$-th type individual equals $\left(1-\tau_{a}^{i}\right) y_{a, t}^{i}=\xi y_{t}$ : i.e. income is completely redistributed. Consequently, this tax scheme naturally suggests two bounds for the progressivity measure, 0 and 1 . The specification of the tax rates in Eq. (8) allows us to rewrite the first-order necessary conditions in Eqs. (4) and (5) as

$$
\begin{gathered}
\left(c_{1, t}^{i}\right)^{-\sigma_{1}}\left(1-n_{t}^{i}\right)^{\sigma_{2}}=\beta\left(c_{2, t+1}^{i}\right)^{-\sigma_{1}}\left[1+(1-\phi)\left(1-\tau_{2}^{i}\right) r_{t+1}\right], \\
\left(1-n_{t}^{i}\right) \theta^{i} w_{t}(1-\phi)\left(1-\tau_{1}^{i}\right)=\frac{\sigma_{2}}{1-\sigma_{1}} c_{1, t}^{i},
\end{gathered}
$$

for $i=1,2, \ldots I$. Simple inspection of Eqs. (9) and (10) shows that along the balanced growth path, at which the interest rate is constant [see Eq. (7)], $c_{1, t}^{i}, c_{2, t}^{i}$ and $w_{t}$ must grow at the same rate, thereby guaranteeing that $n_{t}^{i}=n^{i}$ for all $t$.

\section{Competitive equilibrium}

Once both the private sector and the government have been introduced, I next solve for the competitive equilibrium.

Labor market equilibrium Equilibrium in the labor market is trivially obtained. Using $J_{t}$ to denote the number of young individuals at $t$, equilibrium in the labor market (expressed in efficiency units) is given by

$$
N_{t}=J_{t} \times \tilde{n}_{t}
$$

where the left-hand side denotes aggregate labor demand and the right-hand side represents aggregate labor supply, $\tilde{n}_{t}$ standing for average effective labor supply per young individual, i.e. $\tilde{n}_{t} \equiv \sum_{i=1}^{I} \theta^{i} p^{i} n_{t}^{i}$, and $p^{i}$ denoting the (time invariant) proportion of $i$-th type individuals (i.e. $p^{i} \geq 0$ and $\sum_{i=1}^{I} p^{i}=1$ ).

Goods market equilibrium As is standard in 2-period OLG models with no financial assets at birth, equilibrium in the goods market requires that the aggregate of young individuals' savings be equal to the next period's aggregate stock of capital. Therefore, it must be the case that $\tilde{s}_{t}=(1+m) \hat{k}_{t+1}$, where $\tilde{s}_{t} \equiv \sum_{i=1}^{I} p^{i} s_{t}^{i}$ represents average savings per young individual, and $\hat{k}_{t} \equiv K_{t} / J_{t}$, i.e. the aggregate stock of capital per young individual as of time $t$.

Tax rates in equilibrium We are now ready to solve for the tax rates that young and old individuals face. Firstly, from Eqs. (2) and (7), the $i$-th type young individual's gross income at time $t$ equals

$$
y_{1, t}^{i}=(1-\alpha) \theta^{i} n_{t}^{i} A k_{t},
$$

for $i=1,2, \ldots, I$. Secondly, from Eqs. (3) and (7), one obtains that the $i$-th type old individual's (taxable) income at time $t$ equals

$$
y_{2, t}^{i}=s_{t-1}^{i}(\alpha A-\delta),
$$


for $i=1,2, \ldots I$. Third, the aggregate income across young individuals as of time $t$ is given by $\sum_{i}^{I} p^{i} J_{t} y_{1, t}^{i}=J_{t}(1-\alpha) A \hat{k}_{t}$, where I have used Eqs. (11) and (12). Denoting the number of old individuals at time $t$ as $V_{t}$, the aggregate income across old individuals at time $t$ is given by $\sum_{i}^{I} p^{i} V_{t} y_{2, t}^{i}=V_{t}(\alpha A-\delta)(1+m) \hat{k}_{t}$, where I have used the equilibrium condition in the goods market and Eq. (13). Therefore, noting that $V_{t}=J_{t}(1+m)^{-1}$, aggregate (taxable) income at time $t$ is given by $(A-\delta) J_{t} \hat{k}_{t}{ }^{7}$ Or, equivalently, per capita income at time $t, y_{t}$, equals

$$
y_{t}=\frac{(A-\delta) \hat{k}_{t}}{1+(1+m)^{-1}} .
$$

Fourth, from Eqs. (12) to (14) it is straightforward to obtain the relative before-tax incomes of the $i$-th type young and old individuals, $y_{1, t}^{i} / y_{t}$ and $y_{2, t}^{i} / y_{t}$ respectively, as

$$
\frac{y_{1, t}^{i}}{y_{t}}=\frac{(1-\alpha) A\left[1+(1+m)^{-1}\right]}{A-\delta} \eta^{i}, \quad \frac{y_{2, t}^{i}}{y_{t}}=\frac{(\alpha A-\delta)(2+m)}{A-\delta} \mu^{i},
$$

for $i=1,2, \ldots I$, where $\eta^{i} \equiv \theta^{i} n_{t}^{i} / \tilde{n}_{t}$ and $\mu^{i} \equiv s_{t-1}^{i} / \tilde{s}_{t-1}$ denote the shares respectively of (effective) labor supply and savings of the $i$-th type individual. Therefore, relative before-tax incomes do depend on government policy [characterized by parameters $\gamma, \xi$ and $\phi$ ] through the effect of tax rates on relative labor supplies (the $\eta^{i}$,s) and savings (the $\mu^{i}$ 's). Substituting $y_{1, t}^{i} / y_{t}$ and $y_{2, t}^{i} / y_{t}$ from Eq. (15) into Eq. (8) finally yields the equilibrium average tax rates, $\tau_{1}^{i}$ and $\tau_{2}^{i}$, respectively as

$$
\begin{aligned}
\tau_{1}^{i}=1-\xi & \left\{\frac{(1-\alpha) A\left[1+(1+m)^{-1}\right]}{A-\delta} \eta^{i}\right\}^{-\phi}, \quad \text { and } \\
\tau_{2}^{i} & =1-\xi\left\{\frac{(\alpha A-\delta)(2+m)}{A-\delta} \mu^{i}\right\}^{-\phi},
\end{aligned}
$$

for $i=1,2, \ldots I$. Note that relative before-tax incomes (and, therefore, the tax rates) are time-invariant (because, as shown below, the $\eta^{i}$,s and the $\mu^{i}$, s are also time invariant).

Fifth, I impose the condition of government budget balance on a period basis, $\gamma Y_{t}=\sum_{i}^{I} J_{t} \times p^{i} \times \tau_{1, t}^{i} \times y_{1, t}^{i}+\sum_{i}^{I} V_{t} \times p^{i} \times \tau_{2, t}^{i} \times y_{2, t}^{i}$, where the left-hand side denotes government spending. The right-hand side represents income tax proceeds: the first term denotes taxes paid by the young, while the second term represents taxes paid by the old.

It can be shown that the average (income weighted) of the difference between 1 and the individuals' marginal tax rates is given by $(1-\phi) \times\left[\sum_{i}^{I} p^{i} \times\left(1-\tau_{1, t}^{i}\right) \times y_{1, t}^{i}+\right.$ $\left.(1+m)^{-1} \sum_{i}^{I} p^{i} \times\left(1-\tau_{2, t}^{i}\right) \times y_{2, t}^{i}\right] /\left[\sum_{i}^{I} p^{i} \times y_{1, t}^{i}+(1+m)^{-1} \sum_{i}^{I} p^{i} \times y_{2, t}^{i}\right]$. But the term multiplying $1-\phi$ is nothing but the average of the difference between 1 and

$\overline{7 \text { Recall that capital depreciation }}$ is assumed completely deductible. 
the individuals' average tax rates. Therefore, $\phi$ represents not only the progressivity measure at the individual level, but also economy-wide.

Growth In this paper I solve for the equilibrium growth rate of the stock of capital per young individual between date $t$ and $t+1$, i.e. $g=\left(\hat{k}_{t+1}-\hat{k}_{t}\right) / \hat{k}_{t}$. Given a constant population growth rate, the growth rate of the stock of capital per capita is also $g$, and so is the growth rate of the stock of capital per unit of labor. Thus, the condition for equilibrium in the goods market can be rewritten as

$$
\tilde{s}_{t}=(1+m)(1+g) \hat{k}_{t} .
$$

Some remarks follow. First, the equilibrium growth rate, $g$, is constant always, a standard feature of $A K$ growth models. And, second, all per capita variables grow at the same rate. Thus, from Eq. (14) the (gross) rate of growth of $y_{t}$ is given by $y_{t+1} / y_{t}=1+g$. From Eqs. (2), (7) and (8), one has that $c_{1, t}^{i} / \hat{k}_{t}=\left(1-\tau_{1}^{i}\right) \eta^{i}(1-$ $\alpha) A-\mu^{i}(1+m)(1+g)$ is constant, for $i=1,2, \ldots I$. Further, from Eq. (2) and (7), one obtains that $s_{t}^{i} / \hat{k}_{t}$ is also constant and so must be $\tilde{s}_{t} / \hat{k}_{t}$ [see Eq. (18)]. Finally, from Eqs. (3), (7) and (18) it follows that $c_{2, t} / \hat{k}_{t}=\mu^{i}(1+m)\left(1-\tau_{2}^{i}\right)(\alpha A-\delta)$ is constant too. Therefore, if policy parameters $\gamma, \xi$ and $\phi$ are constant, then $y_{t}, c_{1, t}, s_{t}^{i}, c_{2, t}, \hat{k}_{t}$ and $k_{t}$ would grow at the same rate, $g$.

We are now in a position to define rigorously the competitive equilibrium.

A competitive equilibrium for this economy is a set of sequences of allocations $\left\{c_{1, t}^{i}, n_{t}^{i}, c_{2, t}^{i}, s_{t}^{i}, k_{t+1}, y_{t}\right\}_{t=0, i=1}^{t=\infty, i=I}$, and factor prices for labor and capital $\left\{w_{t}, r\right\}_{t=0}^{t=\infty}$, a constant growth rate for per capita variables, $g$, and constant income tax rates, $\left\{\tau_{1}^{i}, \tau_{2}^{i}\right\}_{i=1}^{i=I}$, such that for a government expenditure to $G D P$ ratio, $\gamma$, tax code parameters $\xi$ and $\phi$, and some initial $\hat{k}_{0}>0$, at any time $t$, households maximize utility [Eqs. (2), (3), (9) and (10) hold]; firms maximize profits [Eq. (7) holds]; the government budget equations hold [Eqs. (16) and (17) plus budget balance hold]; markets for labor and physical capital clear [Eqs. (11) and (18) hold], per capita income is given by Eq. (14); and the growth rate $g$ is given by $g=\left(\hat{k}_{t+1}-\hat{k}_{t}\right) / \hat{k}_{t}$, where $\hat{k}_{t} \equiv k_{t} \times \tilde{n}$.

Given that the economy grows over time, and in order to solve the model numerically, per capita variables must be redefined relative to some variable that grows at the same rate so that the ratios along the balanced-growth path remain constant. A natural candidate for that purpose is the stock of capital per young individual, $\hat{k}_{t}$. Therefore, the competitive equilibrium is defined in terms of transformed variables, so that some of the equations in Definition 1 must be rewritten accordingly. Thus, first- and second-period budget constraints in Eqs. (2) and (3) become

$$
\begin{gathered}
\hat{c}_{1}^{i}+\hat{s}^{i}=\theta^{i} n^{i}\left(1-\tau_{1}^{i}\right) \hat{w}, \\
\hat{c}_{2}^{i}=\hat{s}^{i}(1+g)^{-1}\left[1+\left(1-\tau_{2}^{i}\right) r\right],
\end{gathered}
$$

for $i=1,2, \ldots I$, respectively, where, by definition, $\hat{c}_{1}^{i} \equiv c_{1, t}^{i} / \hat{k}_{t}, \hat{c}_{2}^{i} \equiv c_{2, t}^{i} / \hat{k}_{t}$, $\hat{s}^{i} \equiv s_{t}^{i} / \hat{k}_{t}$, and $\hat{w} \equiv(1-\alpha) A / \tilde{n}$. Similarly, the Euler equation in (9) and the optimal consumption-leisure choice equation in (10) become 


$$
\begin{gathered}
\left(\hat{c}_{1}^{i}\right)^{-\sigma_{1}}\left(1-n^{i}\right)^{\sigma_{2}}=\beta\left[\hat{c}_{2}^{i}(1+g)\right]^{-\sigma_{1}}\left[1+(1-\varphi)\left(1-\tau_{2}^{i}\right) r\right] \\
\left(1-n^{i}\right) \theta^{i} \hat{w}(1-\phi)\left(1-\tau_{1}^{i}\right)=\frac{\sigma_{2}}{1-\sigma_{1}} \hat{c}_{1}^{i}
\end{gathered}
$$

for $i=1,2, \ldots I$. The goods market equilibrium condition in Eq. (18) becomes

$$
\hat{s}=(1+g)(1+m),
$$

where $\hat{s} \equiv \sum_{i=1}^{I} p^{i} \hat{s}^{i}=\tilde{s}_{t} / \hat{k}_{t}$, and per capita income in Eq. (14) is given by $\hat{y} \equiv$ $y_{t} / \hat{k}_{t}=(A-\delta) /\left[1+(1+m)^{-1}\right]$. The rest of the equations in Definition 1 need not be rewritten.

The endogenous variables in Definition 1 are highly non-linear functions of parameters in household preferences, firms' technological constraint and government tax policy. As a consequence, the very setup of the model prevents one from obtaining analytical results, so that numerical methods must be used to solve for the equilibrium and the response of the economy to government policy changes.

\section{Welfare}

A final issue to consider is that of welfare, i.e. what the relationship is between income tax code progressivity and social welfare. Assume that at time $t$ the government sought the progressivity index that maximized a discounted sum of the average life-cycle utility of all current and future generations, $\sum_{j=-1}^{\infty} D^{j} \sum_{i=1}^{I} p^{i} J_{t+j} U$ $\left(c_{1, t+j}^{i}, c_{2, t+j+1}^{i}, n_{t+j}^{i}\right)$, for some social discount factor $D>0$. After normalizing the number of young individuals at time $t$ so that $J_{t} \equiv 1$, recalling that $m$ denotes the population growth rate, grouping the contemporaneous terms together and ignoring the constant term $\left(c_{1, t-1}^{i}\right)^{1-\sigma_{1}}\left(1-n_{t-1}^{i}\right)^{\sigma_{2}} /\left(1-\sigma_{1}\right)$, the objective function can be rewritten as

$$
\sum_{j=0}^{\infty} \hat{D}^{j} \sum_{i=1}^{I} p^{i}\left\{\frac{\left(c_{1, t+j}^{i}\right)^{1-\sigma_{1}}\left(1-n_{t+j}^{i}\right)^{\sigma_{2}}}{1-\sigma_{1}}+\frac{\beta}{\hat{D}} \frac{\left(c_{2, t+j}^{i}\right)^{1-\sigma_{1}}}{1-\sigma_{1}}\right\}
$$

for $\hat{D} \equiv D(1+m)$ (see De la Croix and Michel 2002, chap. 2). Dividing the expression in Eq. (24) by $\hat{k}_{t}^{1-\sigma_{1}}=\left[\hat{k}_{t+j}(1+g)^{-j}\right]^{1-\sigma_{1}}$ and rearranging terms, one obtains the (normalized) social welfare function to be maximized as

$$
\sum_{j=0}^{\infty} \hat{D}^{j} \sum_{i=1}^{I} p^{i}\left\{\frac{\left[\hat{c}_{1}^{i}(1+g)\right]^{1-\sigma_{1}}\left(1-n^{i}\right)^{\sigma_{2}}}{1-\sigma_{1}}+\frac{\beta}{\hat{D}} \frac{\left[\hat{c}_{2}^{i}(1+g)\right]^{1-\sigma_{1}}}{1-\sigma_{1}}\right\},
$$


where $\hat{c}_{1}^{i}$ and $\hat{c}_{2}^{i}$ have been defined right after Definition 1 in Sect. 3. ${ }^{8}$ Finally, after further rearranging Eq. (25), this can be rewritten as

$$
\begin{aligned}
S W F(\phi, D) \equiv & \sum_{i=1}^{I} p^{i}\left\{\frac{\left[\hat{c}_{1}^{i}(\phi)\right]^{1-\sigma_{1}}\left[1-n^{i}(\phi)\right]^{\sigma_{2}}}{1-\sigma_{1}}+\frac{\beta}{\hat{D}} \frac{\left[\hat{c}_{2}^{i}(\phi)\right]^{1-\sigma_{1}}}{1-\sigma_{1}}\right\} \\
& \times \sum_{j=0}^{\infty}\left\{\hat{D}[1+g(\phi)]^{1-\sigma_{1}}\right\}^{j},
\end{aligned}
$$

where individual optimal decisions, $\hat{c}_{1}^{i}, n^{i}$ and $\hat{c}_{2}^{i}$, as well as the growth rate, $g$, are made explicitly dependent on $\phi$, and function $S W F$ is explicitly made dependent of $\phi$ and $D$. For the problem to be well defined, $S W F(\phi, D)$ must be bounded above; or, in other words, $D, m, \sigma_{1}$ and equilibrium $g$ must be such that $D<(1+g)^{\sigma_{1}-1} /(1+m) .{ }^{9}$ Thus, assuming that this condition holds, Eq. (26) leads to

$$
\begin{aligned}
S W F(\phi, D) \equiv & \frac{1}{\left(\sigma_{1}-1\right)\left\{\hat{D}[1+g(\phi)]^{1-\sigma_{1}}-1\right\}} \\
& \times \sum_{i=1}^{I} p^{i}\left\{\left[\hat{c}_{1}^{i}(\phi)\right]^{1-\sigma_{1}}\left[1-n^{i}(\phi)\right]^{\sigma_{2}}+\frac{\beta}{\hat{D}}\left[\hat{c}_{2}^{i}(\phi)\right]^{1-\sigma_{1}}\right\} .
\end{aligned}
$$

Finding an analytical expression relating $\operatorname{SWF}(\phi, D)$ to $\phi$ would be unfeasible. As usually seen in the literature, though, one way to quantify the gain in utility as a result of some given tax policy change relative to the benchmark (or status quo) case consists of calculating the proportional change in life-time benchmark consumption that would leave agents indifferent between the two situations (in short, the consumptionequivalent variation, which can always be computed numerically).

Before obtaining such a variation, some explanation about how a change in $\phi$ is implemented in this economy is needed. Imagine that the economy were in benchmark economy at $t-1$, and that an unannounced change in $\phi$ were introduced at time $t$. Young individuals (born at time $t$ ) would make their optimal plans about consumption, saving and labor supply according to the new tax regime (characterized by $\phi=\phi^{*}$ ), so that the economy would be in the new steady state at $t+1$. Old individuals at time $t$ (born at $t-1$ ) however, would have already made their saving (and first-period consumption and labor supply) decisions at $t-1$ according to the old tax regime (characterized by $\phi=\phi^{0}$ ), so that they would be forced to change their optimal plans for second-period consumption. The assumption made is that old individuals at time

\footnotetext{
8 Equation (25) can be easily interpreted as follows. Imagine that the utility function in Eq. (1) depended on the number of pounds of apples that one individual born at $t+j$ consumed when young, $c_{1, t+j}$, and when old, $c_{2, t+j+1}$. We could always rewrite it in terms of the number of apples eaten by that individual when young and when old ( $\hat{c}_{1}$ and $\hat{c}_{2}$ respectively) if the weight of apples between $t+j$ and $t+j+1$ grew at a rate $g$.

9 Note that if $\sigma_{1}>1$ (as will be the case in the numerical exercise carried out below), the upper bound on $D$ is increasing in $g$. This implies that in order to make welfare comparisons for different values of $\phi, D$ must be low enough as higher progressivity levels will lead to lower equilibrium growth rates.
} 
$t$ would pay taxes with the new progressivity index, $\phi^{*}$, but with a transitory value for parameter $\xi$ in Eq. (8) which guaranteed that government budget would balance at time $t$.

Thus, denoting that change by $\lambda$, it can be shown after some algebra that $\lambda$ is given by

$$
\lambda\left(\phi^{*}, \phi^{0}, D\right)=\left[\frac{\Omega+\hat{D}\left[1+g\left(\phi^{*}\right)\right]^{1-\sigma_{1}} \times S W F\left(\phi^{*}, D\right)}{S W F\left(\phi^{0}, D\right)}\right]^{\frac{1}{1-\sigma_{1}}}-1,
$$

for $\sigma_{1} \neq 1$, where

$$
\Omega \equiv \sum_{i=1}^{I} p^{i}\left\{\frac{\left[\hat{c}_{1}^{i}\left(\phi^{*}\right)\right]^{1-\sigma_{1}}\left[1-n^{i}\left(\phi^{*}\right)\right]^{\sigma_{2}}}{1-\sigma_{1}}+\frac{\beta}{\hat{D}} \frac{\left[\tilde{c}_{2}^{i}\left(\phi^{0}, \phi^{*}\right)\right]^{1-\sigma_{1}}}{1-\sigma_{1}}\right\},
$$

$\tilde{c}_{2}^{i}\left(\phi^{0}, \phi^{*}\right)$ denoting the (normalized) second-period consumption for an $i$-th type individual who is born in a $\phi^{0}$ tax regime and dies in a $\phi^{*}$ tax regime.

\section{Results}

\subsection{Calibration}

Here I set the parameter values for the benchmark case that I use in the simulation exercises in the next Section. In choosing the appropriate values, I will make the model economy mimic some stylized facts of the US economy. Table 1 shows the parameter values, Table 2 compares the simulated equilibrium aggregate values to the target values of the corresponding variables, and Table 3 shows the benchmark individual equilibrium. $^{10}$

Preferences Parameter $\beta$ is set equal to 0.7397 . I obtain this value by assuming a yearly subjective discount factor of 0.99 (just slightly $<1$ ), and that 1 model period represents 30 years of calendar time. The reason for this choice (above more often used values in the literature) is that a negative relationship between the subjective discount factor and the equilibrium interest rate appears. ${ }^{11}$ I set $\sigma_{1}=2$, which implies $I E S=0.5$, "the median of the estimates in the literature." 12 Parameter $\sigma_{2}$ is obtained

\footnotetext{
10 In general, all parameters are expected to influence all equilibrium variables. When a particular parameter is associated with a particular endogenous variable, it is because the former is expected to affect the latter quantitatively most.

11 The equilibrium yearly interest rate turns out to equal $8.7 \%$. Although a seemingly too high value and above standards, Poterba (1998) found a real return on capital of $8.6 \%$ using NIPA data on capital income flows and BEA capital stock data, and Gomme and Rupert (2007) obtained an implied pre-tax real interest rate of $13.2 \%$ in an article specifically focusing on calibration of macroeconomic models. Simple inspection of Eq. (7) explains why it is difficult to mimic observed interest rates in this economy: $\alpha$ is reserved to replicate the capital income share, $A$ turns out to be the key parameter to replicate the equilibrium growth rate, and $\delta$ is bounded between 0 and 1 .
}

12 See Caldara et al. (2009). 
Table 1 Parameter values: benchmark case

\begin{tabular}{llll}
\hline Preferences & $\beta=0.7397$ & $\sigma_{1}=2.00$ & $\sigma_{2}=-2.2445$ \\
Demographics & $m=0.368$ & $\theta^{1}=1.000$ & $\theta^{2}=1.560 \quad \theta^{3}=1.959$ \\
& $\theta^{4}=2.420$ & $\theta^{5}=3.676$ & $p^{i}=0.2$ for $i=1,2, \ldots, 5$ \\
Technology & $\alpha=0.377$ & $\delta=0.996$ & $A=32.820$ \\
Government & $\gamma=0.1543$ & $\phi=0.036$ & $\xi=0.8437$ \\
\hline
\end{tabular}

Figures correspond to the exogenous and calibrated model parameters

Table 2 Simulated and target aggregate values

\begin{tabular}{lll}
\hline Variable & Simulated (\%) & Target (\%) \\
\hline Annual per capita growth rate & 1.92 & 1.92 \\
Average hours of work & $1 / 3$ & $1 / 3$ \\
Annual population growth rate & 1.05 & 1.05 \\
Capital income share & 37.7 & 37.7 \\
Income tax progressivity index & 0.036 & 0.036 \\
Government consumption share & 15.43 & 15.43 \\
Annual investment-GDP ratio & 18.1 & 18.1 \\
Share of total after tax & & \\
Lifetime income by quintile & & \\
First quintile & 9.7 & 9.7 \\
Second quintile & 14.9 & 14.9 \\
Third quintile & 18.56 & 18.56 \\
Fourth quintile & 22.76 & 22.76 \\
Fifth quintile & 34.08 & 34.08 \\
\hline
\end{tabular}

Figures in column 2 correspond to the simulated values of magnitudes listed in column 1 Figures in column 3 correspond to the respective observed values

endogenously and equals -2.2445 . In this way, the average labor supply, $\sum_{i}^{I} p^{i} n^{i}$, equals 1/3, a standard choice (see e.g. Conesa et al. 2009; Fuentes-Albero et al. 2009). ${ }^{13}$ The additional result is a Marshallian labor supply elasticity of 0.003 with respect to the after-tax wage rate for the average individual, i.e. that with an average skill level. Thus, differences among the labor supplies of the 5 individuals that I will introduce a few lines below turn out to be negligible: $n^{1}=0.3330, n^{2}=0.3332, n^{3}=0.3333$, $n^{4}=0.3334$ and $n^{5}=0.3336$. Some remarks on this issue follow. First, this can be no surprise, but a direct consequence of the preferences represented by Eq. (1). Ideally, labor supply elasticity should also be targeted in the calibration exercise and replicated by this model economy, rather than obtained and ex-post compared to observed values.

13 The U.S. Department of Labor, Bureau of Labor Statistics reports $67 \mathrm{~h}$ per week worked by a married couple between 25 and 54 years in 2000 (see Working in the 21st Century, http://www.bls.gov/opub/ working/page 17b.htm). Assuming $100 \mathrm{~h}$ per week per person as the available discretionary time yields that figure. 
Table 3 Equilibrium individual variables

\begin{tabular}{lllllllll}
\hline Type & $c_{1}^{i} / c_{1}^{1}$ & $c_{2}^{i} / c_{2}^{1}$ & $s^{i} / s^{1}$ & $n^{i}$ & $\tau_{1}^{i}$ & $\tau_{2}^{i}$ & $\hat{\tau}_{1}^{i}$ & $\hat{\tau}_{2}^{i}$ \\
\hline 1 & 1.0 & 1.0 & 1.0 & 0.33302 & 0.136 & 0.128 & 0.167 & 0.160 \\
2 & 1.5 & 1.5 & 1.5 & 0.33323 & 0.150 & 0.142 & 0.181 & 0.173 \\
3 & 1.9 & 1.9 & 1.9 & 0.33334 & 0.157 & 0.149 & 0.187 & 0.180 \\
4 & 2.3 & 2.3 & 2.4 & 0.33344 & 0.163 & 0.155 & 0.194 & 0.186 \\
5 & 3.5 & 3.4 & 3.6 & 0.33364 & 0.176 & 0.168 & 0.206 & 0.198 \\
\hline
\end{tabular}

Individual variables in equilibrium according to the notation introduced in the main text. For each $i$-th type individual, $c_{1}^{i} / c_{1}^{1}, c_{2}^{i} / c_{2}^{1}$ and $s^{i} / s^{1}$ denote relative to type 1 individual young and old consumption and young savings respectively. Additionally, $n^{i}$ : labor supply; $\tau_{1}^{i}$ and $\tau_{2}^{i}$ : average tax rates for young and adult; and $\hat{\tau}_{1}^{i}$ and $\hat{\tau}_{2}^{i}$ : marginal tax rates for young and adult

But, of course, compatibility of preferences with endogenous balanced growth path imposes tight restrictions on those as is well known in the profession (see King et al. 1988). And, second, empirical microeconomic estimates of the elasticity of hours worked for the U.S. economy are substantially low, ranging between -0.1 and 0.2 for men and single women, and 0.1 and 0.3 for married women (see Kimball and Shapiro 2010; McClelland and Mok 2012). ${ }^{14}$

Technology I assume $\alpha=0.377$, thus representing the capital income share. ${ }^{15}$ Parameter $A$ is obtained endogenously and equals 32.820 . This allows one to obtain a (30-year) growth rate of per capita GDP of $g=76.92 \%$, corresponding to an annual growth rate of $g_{a}=1.92 \% .{ }^{16}$ I endogenously obtain $\delta$ in a straightforward manner. Consider the law of motion for the aggregate stock of capital, $K_{a, t}$, on an annual basis, $I_{a, t}=K_{a, t+1}-\left(1-\delta_{a}\right) K_{a, t}$, where $I_{a, t}$ denotes gross investment at period $t$ and $\delta_{a}$ stands for the (annual) physical capital depreciation rate. Assuming a balanced growth rate path for $K_{a, t}$, so that $K_{a, t+1}=K_{a, t}\left(1+g_{a}\right)\left(1+m_{a}\right)$, where $m_{a}$ denotes the annual population growth rate, and (once again) that 1 model period represents 30 years of calendar time, one has that $I_{a, t} / Y_{a, t}=\left[\left(1+g_{a}\right)\left(1+m_{a}\right)-\left(1-\delta_{a}\right)\right] /(A / 30)$, where $Y_{a, t}=(A / 30) K_{a, t}$ trivially denotes annual $G D P$ at period $t$. Equivalently, $I_{a, t} / Y_{a, t}=\left[\left(1+g_{a}\right)\left(1+m_{a}\right)-(1-\delta)^{1 / 30}\right] /(A / 30)$. Finally, assuming an annual

\footnotetext{
14 As Keane (2011) concludes, however, there exists a controversy over the responsiveness of labor supply to changes in wages and taxes: even though (at least for males) most economists believe labor supply elasticities are small, a considerable minority of studies finds large values. Additionally, estimates of small labor supply elasticities based on micro data are consistent with large aggregate labor supply elasticities. This is the result obtained when simple labor supply decision micro models are enriched with the sort of dynamics induced by human capital accumulation, or when macro models allow for presence of the extensive margin (Keane and Rogerson 2012).

15 The Congressional Budget Office (2006, p. 36), reports an average labor income share of 0.623 between 1950 and 2005.

16 Author's calculation for the sample period running between 1980 and 2005. See Table 679. Selected Per Capita Income and Product Measures in Current and Chained (2005) Dollars: 1960 to 2010, in "Income, Expenditures, Poverty, and Wealth", p. 443, U.S. Census Bureau, Statistical Abstract of the United States: 2012.
} 
population growth rate of 0.0105 (to be justified a few lines below), setting $\delta=0.996$ allows one to mimic the observed value for $I_{a, t} / Y_{a, t}, 0.181 .^{17}$

Government I set the government consumption share of GDP, $\gamma$, equal to $15.43 \%$, the observed average value for the sample period running between 1980 and $2000 .{ }^{18}$ As for the income tax progressivity index, I set $\phi=0.036$, the estimated value from Internal Revenue Service micro data for 2000 reported in, Guner et al. (2014a, Table 10 , p. 15). The resulting equilibrium value for parameter $\xi$ in Eq. (8) turns out to equal 0.8437 .

Demographics According to the IMF World Economic Outlook Database, October 2010, the average annual population growth rate between 1980 and 2007 was 0.0105 . Following the above assumption on model periods and calendar time, I set $m=0.368$. As for the skill distribution, $\theta^{1}$ is normalized to 1 . The remaining skill parameters are set to pin down the income distribution. More precisely, assuming a uniform distribution of five types of individuals as in Li and Sarte (2004) (i.e. $\left\{p^{i}\right\}_{i=1}^{I}=$ $0.2, I=5)$, the chosen $\theta$ 's are able to replicate the observed shares of lifetime income (wage earnings), net of taxes and transfers, corresponding to the quintiles in 1986. ${ }^{19}$ Given that the model period represents 30 years, it makes sense to target the distribution of the sum of discounted labor incomes over the same time interval, rather than the observed income distribution in some given single period. As a result of the unavailability of that piece of data, however, the target is proxied by the whole lifetime net-of-tax earnings and matched by the distribution of net-of-tax labor incomes across active (i.e. first-period) individuals. The resulting $\theta$ 's are $\theta^{2}=1.560, \theta^{3}=1.959$, $\theta^{4}=2.420$, and $\theta^{5}=3.676$. As by-products, the model implies both a higher Gini inequality index for market incomes than for after-tax incomes $(0.250 \mathrm{vs}$. 0.243$)$, and very close Gini income inequality indices for labor and capital incomes, the former being slightly higher ( 0.234 vs. 0.229 , respectively) ${ }^{20}$

Three natural patterns of individual behavior arise from the inspection of Table 3 . First, more skilled individuals end up enjoying higher levels of consumption (in both periods), generating higher savings, and facing higher tax rates (both average and marginal). Second, young (i.e. active) individuals are systematically charged higher tax rates than adult (i.e. retired) agents. And, third, labor supply is (almost) invariant across different type individuals.

17 Author's calculation for the sample period 1980-2005. See Bureau of Economic Analysis, Table 1.1.5. Gross Domestic Product, Last Revised on: June 25, 2014, available at http://www.bea.gov/itable/index. cfm.

18 This consists of all government current expenditures for purchases of goods and services (including compensation of employees). It also includes most expenditures on national defense and security, but excludes government military expenditures that are part of government capital formation. See United States: General government final consumption expenditure (\% of GDP), available at http://www.quandl.com/ WORLDBANK/USA_NE_CON_GOVT_ZS-United-States-General-government-final-consumption-exp enditure-of-GDP .

19 Source: author's calculations after Fullerton and Lim Rogers (1993), Tables 4-10. Characteristics of Lifetime Categories, p. 114.

20 It is a natural result that both inequality indices turn out to be so close to each other. Individuals' abilities determine first period (labor) income distribution, and second period (capital) incomes depend only on first period savings. The observed fact, however, is that capital ownership (and income) is more concentrated than labor income (see, e.g. Piketty 2014, p. 174; Piketty and Saez 2014, p. 839). 


\subsection{Findings}

The numerical experiment run in this paper consists of analyzing the effects of changes in income tax progressivity upon long-term growth when this is based on physical capital accumulation, income inequality, and social welfare for a wide enough range of non-negative values of $\phi$ and $D$. Three previous remarks are in order. First, this is a revenue-neutral tax experiment in that changes in $\phi$ are accompanied by the necessary changes in parameter $\xi$, so that total tax revenues represent a constant fraction, $\gamma$, of aggregate output [see Eq. (8) and the condition for government budget balance]. ${ }^{21}$ Second, the theoretically sensible range of values for $\phi$ is the closed interval $[0,1]$ where, as stated in Sect. 2.3, $\phi=0$ represents the flat (proportional) tax case; and $\phi=1$ characterizes the complete redistribution case. Note, however, that the latter extreme case implies that marginal tax rates equal 1 , so that the first order necessary condition in Eq. (10) admits no defined solution. And, third, as already mentioned in Sect. 2.2, the $A K$ feature of the aggregate technology prevents the existence of transitional dynamic effects. Results follow in this order: individual, aggregate, and welfare effects.

Individual effects First, concerning the tax rates, this model economy predicts that, as expected, and for a given $\phi$, higher levels of skills are associated with higher incomes and, consequently, higher average tax rates. And, for any given individual type, active (i.e. young) individuals bear higher tax rates than retirees (i.e. old). ${ }^{22}$ Concerning the response obtained after changes in $\phi$, as the tax code is made more progressive, the average tax rates faced by young individuals of types 4 and 5 become higher, while type 3 young individuals' remain fairly invariant, and type 1 and 2 young individuals' fall. Actually, type 1 individuals become subsidized for values of $\phi$ higher than around 0.23 (i.e. negative average tax rates). As a result, the dispersion of average tax rates faced by young individuals rises which, in turn, will help explain the effect of changes in the tax progressivity upon (net-of-tax) income inequality (see Fig. 1). As for old individuals' average tax rates, responses to a changing $\phi$ are not monotonic. For low enough values (below around 0.55 ), the pattern followed by type 5 individuals' is increasing in $\phi$, while types 1 through 4 individuals' tax rates are decreasing, so that tax rates of type 1 and type 2 individuals would eventually become negative, as anticipated a few lines above. For high values of $\phi$, however, the distorting effect would be so strong, that further increments in $\phi$ would lead to lower average tax rates for type 5 adults (because of the large reduction in their savings) and higher tax rates (but still negative) for type 1 and type 2 adults (see Fig. 2).

\footnotetext{
21 Defining revenue-neutrality as keeping $G / Y$ constant across tax progressivity regimes could be simply justified by saying that most of $G$ are payments to government employees, so that if wages change, $G$ should change proportionally. I owe this interpretation to an anonymous referee.

22 This is a natural result (given the progressive nature of the tax schedule) as equilibrium incomes turn out to be higher for active workers than for retirees. According to Table 670. Money Income of HouseholdsDistribution by Income level and Selected Characteristics: 2006, in U.S. Census Bureau, Statistical Abstract of the United States: 2009, p. 443, household median incomes follow an inverted-U pattern relative to the age of the householder, with the minimum being attained for households whose householder was 65 years old and over.
} 


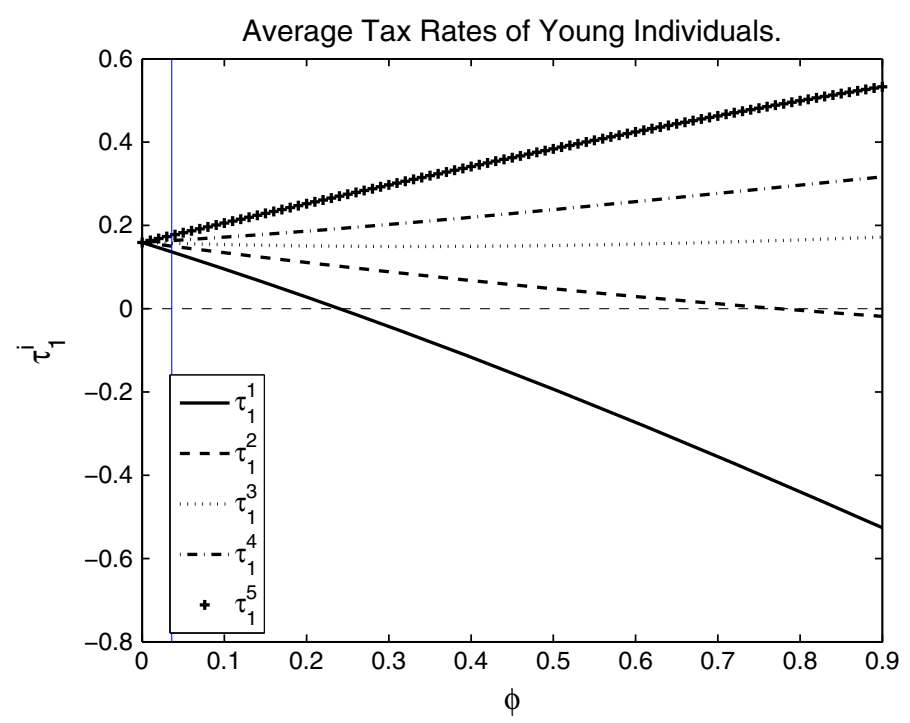

Fig. 1 Progressivity and average tax rates (young)

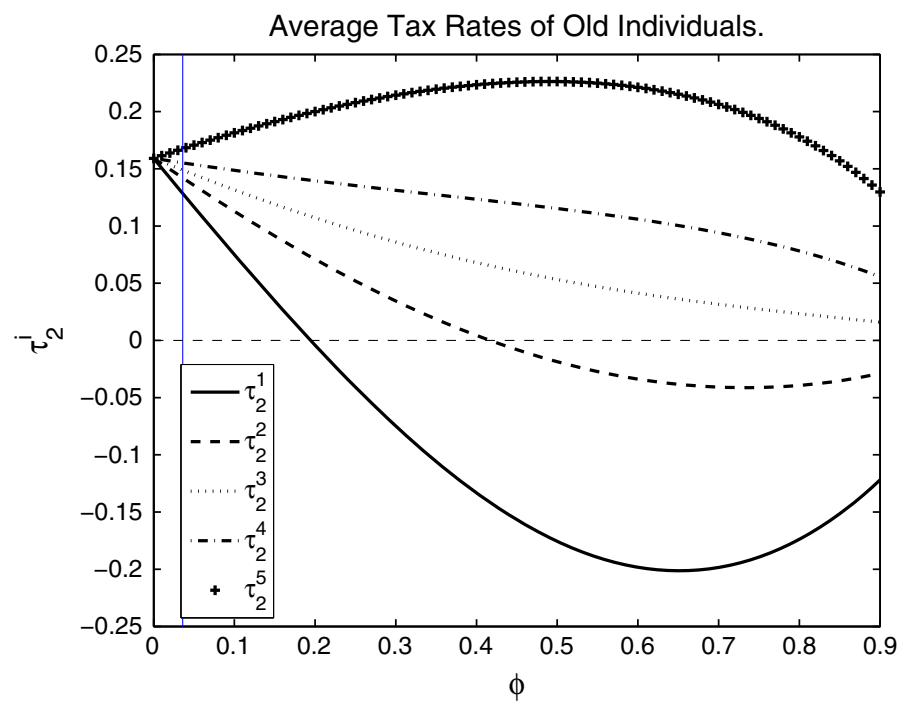

Fig. 2 Progressivity and average tax rates (old)

Second, concerning the labor supply decision, the distortionary effects implied by higher tax progressivity induce a sharp reduction in the labor supply of all types of individuals, with no (substantial) differences across different type individuals (see Fig. 3 where individual labor supplies (almost) overlap each other). As pointed out in the Introduction, this calls for the need to allow for endogenous labor supply when analyzing the effects of taxation on economic growth when this is driven by physical capital accumulation and investment is financed out of young (workers') savings, 


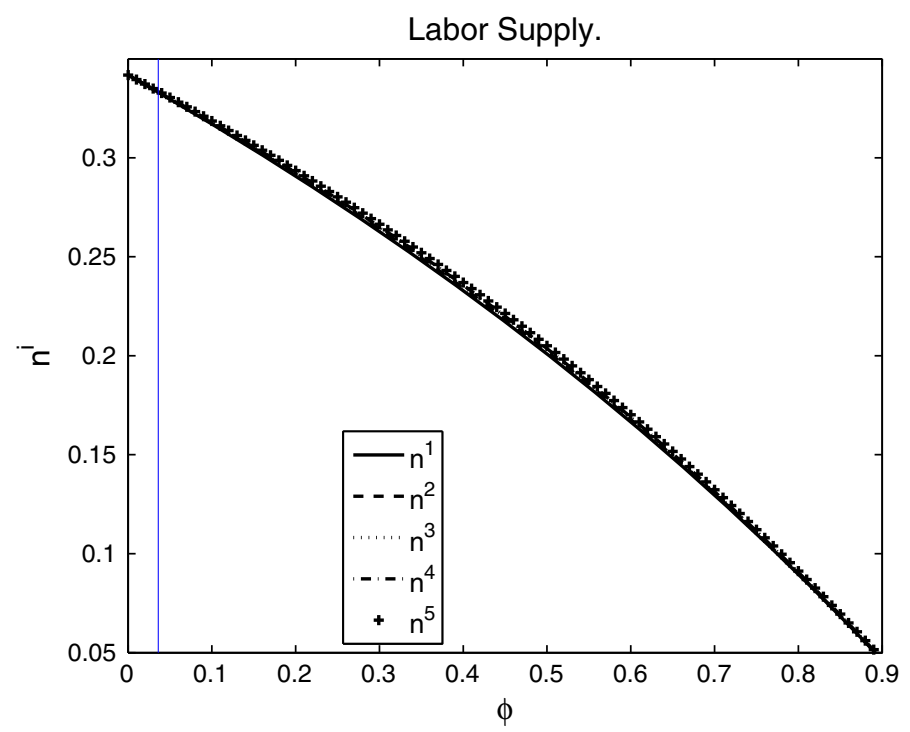

Fig. 3 Progressivity and labor supply

even though (as is the case) labor supply elasticity is close to zero. Heathcote et al. (2014) also find that higher income tax progresssivity discourages labor supply. Along these lines, empirical evidence has found that even with low (zero) Marshallian labor supply elasticity, large Hicks elasticities imply large negative labor supply effects of progressive taxation (see Keane 2011, p. 983).

Third, as for first-period savings, those of individuals of types 3 through 5 fall as a result of increasing progressivity, in particular most skilled ones', type 5. Type 2 individuals' remain fairly constant (except for high levels of $\phi$, around 0.45 , getting lower thereafter); and those of Type 1, i.e. the least skilled, show an increasing pattern (except for unlikely high values of $\phi$ around 0.8 ). This last result is well explained because (as we have just seen above), old type 1 and type 2 individuals face diminishing tax rates as $\phi$ increases, becoming subsidized at some point (see Fig. 4). Needless to say, the response of average first-period savings to be discussed a few lines below is critically relevant in this model economy as economic growth is physical capital driven.

Aggregate effects First, parameter $\xi$ displays a fairly invariant pattern with respect to $\phi$ as it plays a minor role in the tax code: given the reactions of individuals' choices after changes in the progressivity parameter, $\xi$ is just endogenously adjusted so as to obtain budget balance (see Table 4, column 2).

Second, as advanced above, the model economy predicts a positive relationship between $\phi$ and equilibrium leisure. The intuition behind the result is found as a compound effect on young individuals' marginal tax rates and consumption levels after rewriting Eq. (22) as $\left[\sigma_{2} /\left(1-\sigma_{1}\right)\right]\left(1-n^{i}\right)=\hat{c}_{1}^{i} /\left[\theta^{i} \hat{w}\left(1-\hat{t}_{1}^{i}\right)\right]$. Thus, the numerical simulation shows that, following an increment in $\phi$, for most (resp. least) skilled individuals both first-period consumption, $\hat{c}_{1}^{i}$, and the net-of-marginal-tax wage rate in 


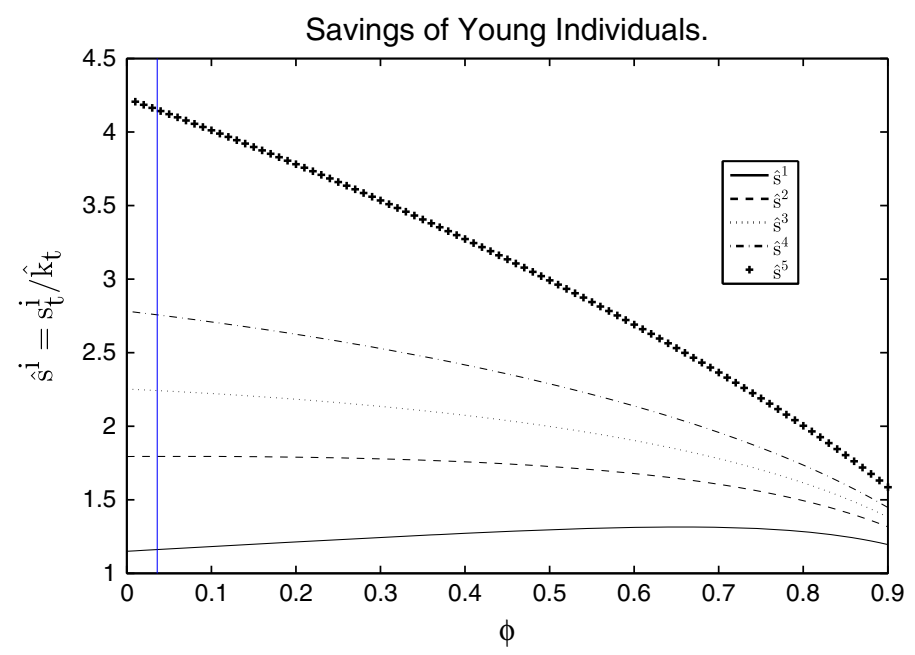

Fig. 4 Progressivity and savings

Table 4 Tax progressivity

\begin{tabular}{lllllll}
\hline$\phi$ & $\xi$ & $\bar{n}$ & $S(\%)$ & $g_{a}(\%)$ & $G_{b}$ & $G_{a}$ \\
\hline 0.0 & 0.84 & 0.34 & 7.44 & 1.95 & 0.25 & 0.25 \\
0.1 & 0.85 & 0.32 & 7.26 & 1.87 & 0.24 & 0.23 \\
0.2 & 0.85 & 0.29 & 7.06 & 1.77 & 0.24 & 0.20 \\
0.3 & 0.86 & 0.26 & 6.84 & 1.66 & 0.23 & 0.18 \\
0.4 & 0.86 & 0.24 & 6.58 & 1.53 & 0.22 & 0.15 \\
0.5 & 0.86 & 0.20 & 6.28 & 1.37 & 0.21 & 0.13 \\
0.6 & 0.86 & 0.17 & 5.92 & 1.18 & 0.20 & 0.11 \\
0.7 & 0.85 & 0.13 & 5.50 & 0.92 & 0.19 & 0.08 \\
0.8 & 0.85 & 0.09 & 4.96 & 0.58 & 0.19 & 0.05 \\
0.9 & 0.85 & 0.05 & 4.22 & 0.04 & 0.20 & 0.02 \\
\hline
\end{tabular}

Aggregate effects Aggregate variables in equilibrium according to the notation introduced in the main text. $\xi$ has been introduced in the tax schedule in Eq. (8); $\bar{n} \equiv \sum_{i=1}^{I} p^{i} n^{i}$ stands for the average hours of work; $S$ denotes the ratio of aggregate young savings to aggregate output; $g_{a}$ denotes the annual per capita GDP growth rate; $G_{b}$ and $G_{a}$ stand for the Gini index of before- tax and net-of-tax incomes respectively

efficiency units, $\theta^{i} \hat{w}\left(1-\hat{t}_{1}^{i}\right)$, turn out to fall (resp. rise) in such a way that the net effect on the right-hand side of the last equation is always positive (see Table 4, column 3 ). As a by-product the model predicts a positive relationship between the (normalized) wage rate, $\hat{w}$, and $\phi$ : from Eq. (7) and the definitions of $\hat{w} \equiv w_{t} / \hat{k}_{t}, \hat{k}_{t} \equiv K_{t} / N_{t}$ and $\tilde{n} \equiv \sum_{i=1}^{I} \theta^{i} p^{i} n^{i}$, one has that $\hat{w}=(1-\alpha) A / \tilde{n}$.

Third, young individuals' aggregate savings relative to aggregate output fall as a result of increasing levels of progressivity as pointed out above: except for the least skilled individuals, higher values of $\phi$ end up inducing lower first-year savings, in particular for the most skilled workers (see Table 4, column 4). 
Fourth, and as a natural consequence of the above (given the role played by physical capital accumulation in this model), the model predicts a negative monotonic relationship between progressivity and growth [see Eq. (18)]. Thus, having denoted the annual growth rate by $g_{a}$, the movement from the benchmark economy (i.e. with a progressive income tax code) to a proportional income tax economy (i.e. $\phi=0$ ) would make $g_{a}$ rise from 1.92 to $1.95 \%$, a gain well below than that suggested by Caucutt et al. (2003) (see Table 4, column 5). Available empirical evidence for OECD countries supports a negative relationship between progressivity of personal income taxes and growth (see, e.g. Arnold 2008, Table 2). One likely reason why the growth effects of lowering the tax progressivity are lower than in Caucutt et al. (2003) is that in the absence of intergenerational links, the distortionary effects of capital income taxation are minimized. ${ }^{23}$

And, fifth, as for the income distribution, the model also predicts a positive relationship between income tax progressivity and equality of income distribution, and higher inequality of before-tax than after-tax incomes. More precisely, the Gini indices of market and net-of-tax incomes, denoted by $G_{b}$ and $G_{a}$ respectively, display a decreasing pattern relative to $\phi$ (see Table 4, columns 6 and 7). This is a natural result because, as discussed above, increments in income tax progressivity lead to increasing tax rates for more skilled agents and lower tax rates for less skilled. After all, given that tax revenues represent a constant fraction of $G D P$, a higher progressivity must lead to a reduction in net-of-tax income inequality. In short, income inequality would be maximized under a proportional tax scheme, $\phi=0$, and any increment in personal income tax progressivity would reduce inequality.

Welfare effects Concerning welfare analysis, simple inspection of Eq. (27) shows that higher progressivity leads to three different effects, one of which turns out to display a negative sign, the second and the third one displaying a positive one. On the one hand, increments in $\phi$ induce lower growth rates and, therefore, reduce the well-being of current individuals and future generations'. This effect is captured by a lower first term of the right-hand side of Eq. (27). Note that the social discount factor, $D$, is a crucial element here: as $D$ increases, so that future generations' well-being is more valued, this lower growth effect of progressivity becomes more relevant, thereby calling for a lower progressivity. On the other hand, higher progressivity levels give rise to lower inequality of after-tax incomes and, therefore, lower dispersion of optimal consumption levels across individuals of different types, and more importantly, as the numerical results reveal, higher levels of leisure. The latter effect is captured by a higher second term of the right-hand side of Eq. (27). The relationship between these three effects could be interpreted as follows: a social planner would always value increasing equality, but that would have the cost lowering consumption growth; increasing leisure would be a (non-negigible) side effect. ${ }^{24}$

Table 5 summarizes the results. The table shows, for alternative values of $D$ (ranging between 0.1 and 1.2, including $\beta=0.7397$ ), and in addition to the aggregates of Table

\footnotetext{
23 As opposed to Caucutt et al. (2003), this model implies (although for the sake of space saving the results are not shown) that assuming proportional taxation, changes (increments) in the flat tax rate do imply changes (reductions) in the equilibrium growth rate.

24 I owe this interpretation to an anonymous referee.
} 
Table 5 Tax progressivity

\begin{tabular}{lrrrrrrrrr}
\hline & \multicolumn{1}{l}{$D$} \\
\cline { 2 - 9 } & \multicolumn{1}{c}{0.1} & 0.2 & \multicolumn{1}{c}{0.3} & 0.4 & \multicolumn{1}{c}{0.5} & 0.6 & 0.7 & $\beta$ & 1.2 \\
\hline$\phi^{W}$ & 0.90 & 0.87 & 0.80 & 0.74 & 0.66 & 0.58 & 0.49 & 0.45 & 0.10 \\
$\lambda^{W}(\%)$ & 62.45 & 60.67 & 54.97 & 47.43 & 38.97 & 30.14 & 21.38 & 18.01 & -15.01 \\
$\xi$ & 0.85 & 0.85 & 0.85 & 0.85 & 0.86 & 0.86 & 0.86 & 0.86 & 0.85 \\
$\bar{n}$ & 0.05 & 0.06 & 0.09 & 0.12 & 0.15 & 0.18 & 0.21 & 0.22 & 0.32 \\
$S(\%)$ & 4.22 & 4.47 & 4.96 & 5.30 & 5.68 & 6.00 & 6.31 & 6.43 & 7.3 \\
$g_{a}(\%)$ & 0.04 & 0.23 & 0.58 & 0.80 & 1.03 & 1.22 & 1.39 & 1.46 & 1.87 \\
$G_{b}$ & 0.20 & 0.19 & 0.19 & 0.19 & 0.20 & 0.21 & 0.21 & 0.21 & 0.24 \\
$G_{a}$ & 0.02 & 0.03 & 0.05 & 0.07 & 0.09 & 0.11 & 0.13 & 0.14 & 0.23 \\
\hline
\end{tabular}

Welfare The table shows the optimal progressivity index $\phi^{W}$ and the associated welfare gain $\lambda^{W}$ [see Eq. (28)], along with some aggregates (see Table 4), for alternative values of the social discount factor $D$. Column 9 has been obtained for $D=\beta=0.7397$, the individual discount factor (see Table 1). Condition $D<(1+g)^{\sigma_{1}-1} /(1+m)$ is violated for $D=\beta$ and $\phi \geq 0$.9. The highest admissible value for $D$ is 1.2 (see note 28 and last column in this Table)

4, the social welfare maximizing progressivity index, $\phi^{W}$, and the associated welfare gain relative to the benchmark case, $\lambda^{W} .{ }^{25}$ The pattern shown in Table 5 is clear. First, the optimal degree of progressivity is always positive. Second, that optimal progressivity level is inversely related to how society values future generations' wellbeing. ${ }^{26}$ And, third, quantitative welfare gains at the optimum, in terms of equivalent variation in consumption, largely depend on the social discount factor: as future wellbeing is more valued, the welfare gains associated with optimal progressivity levels tend to fall.

To illustrate how relatively important these three effects of tax progressivity are, one can think about the following two experiments. Assume, first, that (almost) complete redistributive taxes were optimal, so that $\varphi^{W}=0.9$ (which is actually the case when $D=0.1$ ), with an associated welfare gain of $62.45 \%$ in terms of equivalent variation in consumption (see Table 5, column 2). In this case, the welfare gain exclusively due to eliminating consumption inequality equals $20.45 \%$ as an approximation. ${ }^{27}$

Assume, additionally, that such a low social discount factor meant that the growth effect (which influences future consumption) were negligible. In this case, most of the welfare gain, $42.0 \%=62.45 \%-20.45 \%$, would be attributed to the increment in leisure. Consider, instead, that $\varphi^{W}=0.9$ were optimal regardless of the social

\footnotetext{
25 As noted above, $D$ must not exceed the upper bound $(1+g)^{\sigma_{1}-1} /(1+m)$.

26 See the Introduction in Bakis et al. (2014) for a similar conclusion.

27 This can be obtained in an easy manner. Note that labor supply is (nearly) independent of skill distribution, so that consumption distribution can be approximated by skill distribution. Therefore, an equal consumption distribution can be proxied by an equal skill distribution. Thus, the corresponding welfare gain exclusively due to eliminating inequality can be computed as $\lambda=\left[5 \bar{\theta}^{1-\sigma_{1}} /\left(\sum_{i=1}^{5} \theta_{i}^{1-\sigma_{1}}\right)\right]^{1 /\left(1-\sigma_{1}\right)}-1$, where $\bar{\theta} \equiv 5^{-1} \times \sum_{i=1}^{5} \theta_{i}$, which (for the calibrated values of $\theta_{i}$ shown in Table 1 and $\sigma_{1}=2$ ) equals 0.2045 . I owe this point to an anonymous referee.
} 
Table 6 Complete redistribution $(\phi=0.9)$, social discount factor and welfare

\begin{tabular}{lllllllll}
\hline & $D$ & \multicolumn{1}{c}{} & & & & \\
\cline { 2 - 8 } & 0.1 & 0.2 & 0.3 & 0.4 & 0.5 & 0.6 & 0.7 & $\beta$ \\
\hline$\lambda(\%)$ & 62.45 & 60.16 & 50.14 & 33.06 & 8.19 & -26.57 & -75.33 & - \\
\hline
\end{tabular}

Welfare gains under the assumption of (almost) complete redistribution, i.e. $\phi=0.9$, and alternative social discount factors. Aggregates are the same as those in Table 4, last row. As indicated in Table 5, $\lambda$ cannot be computed when $D=\beta$

discount factor and different values for $D$ were tried. Note that, by construction, the aggregates (leisure, growth and net-of-tax income inequality, in particular) would be the same as those in Table 4, last row. This time differences in welfare gains (or losses) would be exclusively due to differences in the valuation of the fall of the equilibrium growth rates of future consumption (see Table 6). Thus, complete redistribution would be welfare enhancing only for sufficiently low social discount factors: $D \leq 0.5$. For instance, the aforementioned gain in welfare of $62.45 \%$ when $D=0.1$, would become a welfare loss of $75.33 \%$ for $D=0.7$.

Two additional cases are worth pointing out. Consider, first, that $D=\beta$, i.e. the subjective discount factor (see Table 5, column 9). The welfare maximizing progressivity index, 0.45 , and the associated welfare gain, $18.1 \%$, sharply fall compared to just above discussed case of $D=0.1$. Despite both inequality of after-tax incomes and labor supply fall compared to the benchmark economy (from 0.243 to 0.14 , and from 0.33 to 0.22 respectively), the equilibrium annual growth rate falls (from 1.92 to $1.46 \%$ ). Thus, given the relatively high weight on future generations' wellbeing, the reduction in the growth rate explains the lower values of $\varphi^{W}$ and $\lambda^{W}$. Finally, consider the case of the highest admissible weight on future generations, namely $D=1.2 .^{28}$ (see Table 5, column 10 ). Social welfare is maximized by a very low progressivity index, 0.1 , leading to a welfare loss compared to the benchmark economy: $\lambda^{W}=-15.01 \%$. The intuition is straightforward: inequality of after-tax incomes and labor supply are almost the same as in the benchmark economy $(0.243$ vs. 0.23 , and 0.33 vs. 0.32 respectively). However, the equilibrium growth rate is lower than in the benchmark economy (1.92 vs. $1.87 \%$ ) and, and this is the key, the high social discount factor heavily penalizes drops in the growth rate.

So far I have assumed that government spending represents a constant proportion of GDP and that it is neither productive nor enters households' preferences: two assumptions often made in model economies focusing on taxation issues. These lead to two unsatisfactory and related to each other consequences: higher growth rates imply that more (current and future) resources in absolute terms are being wasted, and that welfare effects of income tax policy only depend on how the tax burden is shared by households but not on what the government does with tax revenues. Concerning the latter, several alternatives are open. The government might provide some infrastructure in the form of public capital goods thereby influencing the equilibrium growth rate à la Barro (1990); or it might subsidize human capital accumulation thereby affecting

$\overline{28}$ It can be numerically shown that if $D=1.2$ and $\varphi \geq 0.3$, then $D \geq(1+g)^{\sigma_{1}-1} /(1+m)$. 
equilibrium growth à la Benabou (2002); or it might provide some public consumption good valued by households, so that government expenditure in equilibrium would grow at the same rate as the economy. Bearing in mind how sustained equilibrium is obtained in this model economy, it seems reasonable to choose the last among these three alternatives. This issue is covered in the "Appendix" at the end of the paper. There I show that, first, for a given value of the social discount factor, a higher valuation on the part of individuals for the consumption of the publicly provided good implies a lower welfare maximizing progressivity index. And, second, for a given valuation of the consumption of the publicly provided good, a lower social discount of future generations' well-being calls for a lower welfare maximizing progressivity index. (see the "Appendix" for details).

\section{Conclusions}

This paper has analyzed the effects of income tax progressivity on long-run economic growth, income inequality and social welfare.

The theoretical model used for this purpose is characterized by several key features that, when they are considered together, make the paper differ from the existing literature. The model economy does not allow for analytical solution, so that all the results are numerical in nature. The quantitative implications of the model have been illustrated after calibrating its parameters to mimic some basic stylized facts of the US economy.

The findings of the paper can be classified into three main categories: individual, aggregate, and social welfare related results. Increments in income tax progressivity induce a drop in labor supply of all types of individuals (despite the zero labor supply elasticity implied by preferences). Higher progressivity also reduces savings of all individuals except the least skilled ones'. This result squares with that on tax rates: least skilled individuals' average tax rates fall (even becoming negative, so that least skilled individuals become subsidized), while the rest of individuals' average tax rates rise.

As far as the aggregate effects are concerned, increases in income tax progressivity lead to a fall in aggregate savings, which, given how the growth is modeled, necessarily translates into a drop in the equilibrium growth rate. For instance, eliminating the progressivity and moving to a flat tax regime would raise the equilibrium annual growth rate of per capita GDP from 1.92 to $1.95 \%$. Furthermore, increasing the income tax progressivity reduces the inequality in the distribution of both market and net-of-tax incomes. Introducing a proportional income tax code would increase the Gini indices of before-tax and after-tax incomes by 1 and $3.8 \%$ respectively.

Finally, regarding social welfare effects, optimality suggests the need of a political choice between a more equal distribution of net income and consumption levels across different types of individuals and higher levels of leisure and lower growth rates. The size of the second, negative, effect critically depends on the social discount factor: if the social planner discounts less future generations' well-being, the optimal level of progressivity will be lower. In addition, if the government tax proceeds are devoted to the public provision of some private good rather than disposed, the optimal progressivity level will also depend on how households value this public provision relative 
to private consumption: a higher valuation also implies a lower optimal progressivity level, as progressivity also reduces the growth rate of the government-provided consumption. At any rate, and for the parameter values considered, optimality requires some degree of progressivity.

The paper can be improved in at least three directions: (1) increasing the number of life-time periods to gain more realism, (2) allowing for a richer skill distribution which would allow us to reproduce the observed wage distribution and (3) allowing for a different treatment between labor and capital incomes in the spirit of Conesa et al. (2009), thus abandoning the "comprehensive" or "global" approach.

Acknowledgments This paper has greatly benefited from comments by Mara Cruz Loyo and Amaia Iza. The editor and two anonymous referees provided extremely helpful guidance. The usual disclaimer applies. Financial support from MEC (ECO2012-35820), the Basque Government (DEUI, IT-793-13) and UPV/EHU (UFI 11/46 BETS) is gratefully acknowledged.

Open Access This article is distributed under the terms of the Creative Commons Attribution License which permits any use, distribution, and reproduction in any medium, provided the original author(s) and the source are credited.

\section{Appendix: Welfare sensitivity analysis: a public good in the utility function}

Assume that preferences of an individual born at time $t$ were represented by

$$
\begin{aligned}
& U\left(c_{1, t}^{i}, c_{2, t+1}^{i}, n_{t}^{i}, q_{t}, q_{t+1}\right) \\
& =\frac{\left(c_{1, t}^{i}\right)^{1-\sigma_{1}}\left(1-n_{t}^{i}\right)^{\sigma_{2}}+\pi q_{t}^{1-\sigma_{1}}}{1-\sigma_{1}}+\frac{\beta\left[\left(c_{2, t+1}^{i}\right)^{1-\sigma_{1}}+\pi q_{t+1}^{1-\sigma_{1}}\right]}{1-\sigma_{1}},
\end{aligned}
$$

where $q_{t}$ denotes the per capita quantity of a publicly provided private good at time $t$, and $\pi>0$ represents the relative preference for public good consumption over leisure and private consumption. Note that Eq. (30) implies that preferences are additively separable in private and public consumption, which is consistent with empirical evidence (see Amano and Wirjanto 1998 for the U.S. economy case). Remembering that $G_{t}=\gamma Y_{t}, Y_{t}=A K_{t}$, and expressing total population as the sum of young plus old individuals, one easily obtains that $q_{t}$ equals $\gamma A \hat{k}_{t} /\left[1+(1+m)^{-1}\right]$, so that Definition (3) of competitive equilibrium would need to be only slightly modified to include a new variable, namely $\hat{q} \equiv q_{t} / \hat{k}_{t}$. Given the way in which public good provision has been introduced (i.e. with additive separability), the equilibrium allocation of (private) consumption and leisure is invariant to preference parameter $\pi$. In other words, changes in income tax progressivity will lead to the same individual and aggregate effects obtained in Sect. 5.2, but to different welfare effects.

Assume, as before, that at time $t$ the government sought the progressivity index that maximized a discounted sum of the average life-cycle utility of all current and future generations, $\sum_{j=-1}^{\infty} D^{j} \sum_{i=1}^{I} p^{i} J_{t+j} U\left(c_{1, t}^{i}, c_{2, t+1}^{i}, n_{t}^{i}, q_{t}, q_{t+1}\right)$. Following similar steps as in the previous setup in Sect. 2 without public provision, one would obtain the (normalized) social welfare function to be maximized this time as 


$$
\begin{aligned}
& \operatorname{SWF}^{P}(\phi, \pi, D) \equiv S W F(\phi, D) \\
& +\frac{1}{1-\hat{D}[1+g(\phi)]^{1-\sigma_{1}}}\left\{\frac{\pi \hat{q}^{1-\sigma_{1}}}{1-\sigma_{1}}\left(1+\frac{\beta}{\hat{D}}\right)\right\},
\end{aligned}
$$

where the first term on the right-hand side, $S W F(\phi, D)$, has already been introduced in Eq. (27); and the new, second term on the right-hand side trivially denotes the effect of introducing the public provision. Note that this term depends on how progressivity influences growth, $g(\phi)$; how individuals value public provision, $\pi$; and how future generations's well-being is discounted, $D$. Moreover, $S W F^{P}(\phi, \pi, D)=$ $S W F(\phi, D)$ if and only if $\pi=0$. Proceeding in a similar way as when government tax proceeds were just wasted, it is possible to compute the proportional change in life-time benchmark private consumption that would leave agents indifferent between the resulting equilibrium for some progressivity index $\phi^{*}$ and the equilibrium under the benchmark value $\phi^{0}$. Denoting that change by $\lambda$, it can be shown that $\lambda$ is given by

$$
\begin{aligned}
& \lambda\left(\phi^{*}, \phi^{0}, \pi, D\right) \\
& \quad=\left[\frac{\Omega+\hat{D}\left[1+g\left(\phi^{*}\right)\right]^{1-\sigma_{1}} \times S W F\left(\phi^{*}, D\right)+\Psi\left(\phi^{*}, \pi, D\right)-\Psi\left(\phi^{0}, \pi, D\right)}{S W F\left(\phi^{0}, D\right)}\right]^{\frac{1}{1-\sigma_{1}}}-1,
\end{aligned}
$$

for $\sigma_{1} \neq 1$, where $S W F(\cdot)$ and $\Omega$ have been defined in Eqs. (27) and (29), respectively, and $\Psi(\phi, \pi, D)$ has been introduced to denote the second term on the right-hand side of Eq. (31). The difference $\Psi\left(\phi^{*}, \cdot\right)-\Psi\left(\phi^{0}, \cdot\right)$ trivially gives us different valuation of the public provision between the two tax regimes. Simple inspection of Eqs. (31) and (32) tells us that the welfare change corresponding to a movement in the progressivity index from $\phi^{0}$ to $\phi^{*}$ also depends on how individuals value the public provision (i.e. $\pi$ ).

The results of the experiment are shown in Fig. 5 where, for the same values of the social discount factor $D$ considered en Table 5, different arbitrary values of $\pi$ are tried. In particular, Fig. 5a shows how the social welfare maximizing progressivity index, $\phi^{W}$, relates to $\pi$ for different values for $D$. The pattern is clear. First, for a given value of $D$, a higher valuation on the part of individuals for the consumption of the publicly provided good implies a lower $\phi^{W}$. And, second, for a given $\pi$, a lower social discount of future generations' well-being (i.e. a higher $D$ ), requires a lower $\phi^{W}$.

The reason is a very simple one. The reductions in after-tax income inequality (and, thereby, private consumption) and in the growth rate of (private and public) consumption and the increment in leisure as a result of a higher $\phi$ do not depend on whether the public good is provided or not, the separability assumption of preferences trivially driving the result. However, more progressivity implies lower growth not only of private consumption but also of the private good publicly provided. Therefore, a higher valuation of the public provision will imply a lower optimal progressivity level. And, for any given valuation of the public provision, a higher social discount factor means that more weight is put on the growth effect of consumption (both public and 

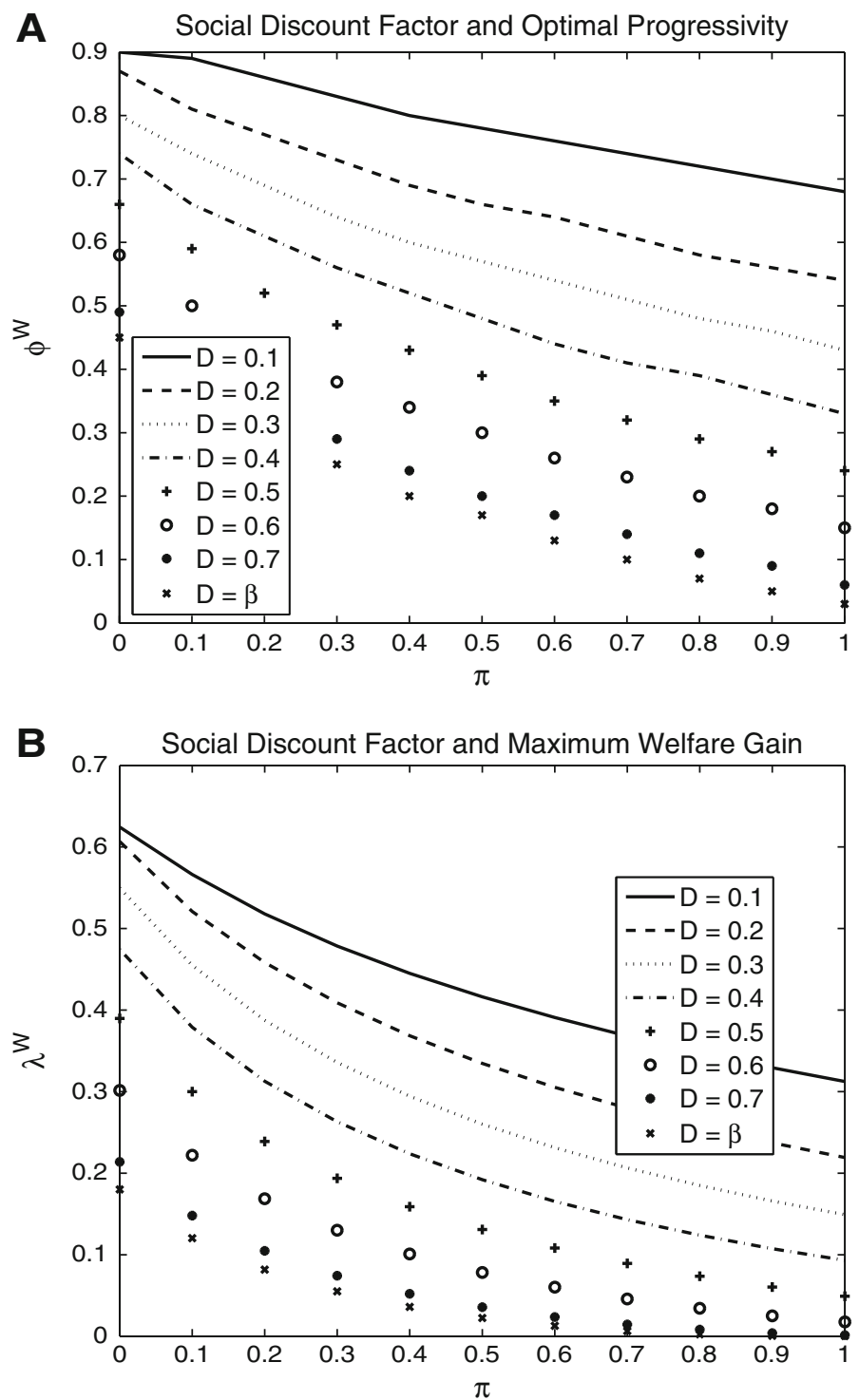

Fig. 5 a Public good: optimal progressivity. b Public good: welfare gain

private) than on the inequality and leisure effects. For completeness, Fig. 5b shows the welfare gain associated to $\phi^{W}, \lambda^{W}$. As one would expect from the discussion just made, $\lambda^{W}$ is decreasing in both $\pi$ and $D$. Needless to say, values of $\lambda^{W}$ largely depend on $\pi$, so that a natural question that arises here, of course, is that of the reasonable value for $\pi$, but empirical work should shed light on this. 


\section{References}

Amano RA, Wirjanto TS (1998) Government expenditures and the permanent-income model. Rev Econ Dyn, 1(3):719-730

Arnold J (2008) Do tax structures affect aggregate economic growth? Empirical evidence from a panel of OECD countries. OECD, Economics Department Working Papers No. 643

Badel A, Huggett M (2014) Taxing top earners: a human capital perspective. Working papers 2014-17, Federal Reserve Bank of St. Louis

Bakis O, Kaymak B, Poschke M (2014) Transitional dynamics and the optimal progressivity of income redistribution. Rev Econ Dyn (forthcoming)

Barro RJ (1990) Government spending in a simple model of endogenous growth. J Polit Econ 98(5, Part 2):S103-S125

Benabou R (2002) Tax and education policy in a heterogeneous-agent economy: what levels of redistribution maximize growth and efficiency? Econometrica 70(2):481-517

Caldara D, Fernández-Villaverde J, Rubio-Ramrez JF, Yao W (2009) Computing DSGE models with recursive preferences. PIER working paper 09-018

Carroll D, Young E (2011) The long run effects of changes in tax progressivity. J Econ Dyn Control 35(9):1451-1473

Caucutt E, İmrohoroğlu S, Kumar K (2003) Growth and welfare analysis of tax progressivity in a heterogeneous-agent model. Rev Econ Dyn 6:546-577

Conesa JC, Krueger D (2006) On the optimal progressivity of the income tax code. J Monet Econ 53(7):14251450

Conesa JC, Kitao S, Krueger D (2009) Taxing capital? Not a bad idea after all!. Am Econ Rev 99:25-48

Congressional Budget Office (2006) How CBO forecasts income. The Congress of the United States August. Pub. No. 2713:35-36

Cunado J, Gil-Alana LA, Pérez de Gracia F (2009) AK growth models: new evidence based on fractional integration and breaking trends. Recherches économiques de Louvain-Louvain Economic Review 75(2):131-149

De la Croix D, Michel P (2002) A theory of economic growth. Cambridge University Press, Cambridge

Diamond P, Saez E (2011) The case for a progressive tax: from basic research to policy recommendations. J Econ Perspect 25(4):165-190

Echevarria CA (2012) Income tax progressivity physical capital, aggregate uncertainty and long-run growth in an OLG economy. J Macroecon 34:955-974

Echevarria CA (2013) A note on infrastructure expenditure, uncertainty and growth. Manch School 81(6):941-960

Farmer REA, Lahiri A (2006) Economic growth in an interdependent economy. Econ J 116(October):969990

Fuentes-Albero C, Kryshko M, Ros-Rull JV, Santaeulàlia-Llopis R, Schorfheide F (2009) Methods versus substance: measuring the effects of technology shocks on hours. Federal Reserve Bank of Minneapolis, Research Department Staff Report 433, August

Fullerton D, Lim Rogers D (1993) Who bears the lifetime tax burden?. The Brookings Institution, Washington D.C

Gervais M (2009) On the optimality of age-dependent taxes and the progressive US tax system. University of Southampton, Discussion Papers in Economics and Econometrics No 0905

Gomme P, Rupert P (2007) Theory, measurement and calibration of macroeconomic models. J Monet Econ 54:460-497

Guner N, Kaygusuz R, Ventura G (2014a) Income taxation of U.S. households: facts and parametric estimates. Rev Econ Dyn 17(4):559-581

Guner N, Lopez-Daneri M, Ventura G (2014b) Heterogeneity and government revenues: higher taxes at the top? IZA discussion paper series no. 8335, July

Heathcote J, Storesletten K, Violante GL(2014) Optimal tax progressivity: an analytical framework. Federal Reserve Bank of Minneapolis. Research Department. Staff Report 496, January

Hubbard RG, Judd KL (1986) Liquidity constraints fiscal policy, and consumption. Brook Papers Econ Activ 1:1-50

Jones CI (1995) Time series tests of endogenous growth models. Q J Econ 110(2):495-525

Keane MP (2011) Labor supply and taxes: a survey. J Econ Lit 49(4):961-1075 
Keane M, Rogerson R (2012) Micro and macro labor supply elasticities: a reassessment of conventional wisdom. J Econ Lit 50(2):464-476

Kimball MS, Shapiro MD (2010) Labor supply: are the income and substitution effects both large or small? Mimeo, previously circulated as NBER Working Paper Series, WP 14208

Kindermann F, Krueger D (2014) The redistributive benefits of progressive labor and capital income taxation: how to best screw (or Not) the top $1 \%$, mimeo

King RG, Plosser C, Rebelo ST (1988) Production, growth and business cycles I. The basic neoclassical model. J Monet Econ 21:195-232

Kleinbard ED (2010) An American dual income tax: Nordic precedents. Northwest J Law Soc Policy 513:41-86

Li D (2002) Is the AK model still alive? The long-run relation between growth and investment re-examined. Can J Econ 35(1):92-114

Li W, Sarte PD (2004) Progressive taxation and long-run growth. Am Econ Rev 94(5):1705-1716

McClelland R, Mok S (2012) A review of recent research on labor supply elasticities. Working Paper Series, Congressional Budget Office, Washington, D.C., WP 2012-12

Mauro P (1995) Stock markets and growth a brief caveat on precautionary savings. Econ Lett 47:111-116

McGrattan ER (1998) A defense of AK growth models. Federal Reserve Bank Minneap Q Rev 22(4):13-27

Mirrlees JA (1971) An exploration in the theory of optimum income taxation. Rev Econ Stud 38(114):175208

Peterman WB (2014) The effect of endogenous human capital accumulation on optimal taxation. http:// williampeterman.com/researchpage, mimeo

Piketty T (2014) Capital in the 21st century. Harvard University Press, Cambridge

Piketty T, Saez E (2014) Inequality in the long-run. Science 344(838):838-843

Poterba JM (1998) Rate of return to corporate capital and factor shares: new estimates using revised national income accounts and capital stock data. Carnegie Rochester Conf Ser Public Policy 48:211-246

Rebelo S (1991) Long-run policy analysis and long-run growth. J Polit Econ 99(3):500-521

Smith WT (1996) Taxes, uncertainty, and long-term growth. Euro Econ Rev 40:1647-1664

Tang X, King I (2005) A comment on Roland Benabou's, Tax and education policy in a heterogeneous-agent economy: what levels of redistribution maximize growth and efficiency? Econometrica 73(3):10031004 